\title{
Transcription Factor Networks in Leaves of Cichorium endivia: New Insights into the Relationship between Photosynthesis and Leaf Development
}

\author{
Giulio Testone ${ }^{1,+}\left(\mathbb{C}\right.$, Elena Baldoni $\left.{ }^{1,2,+}{ }^{(}\right)$, Maria Adelaide Iannelli ${ }^{1, \dagger}$, Chiara Nicolodi ${ }^{1}$, \\ Elisabetta Di Giacomo ${ }^{1}$, Fabrizio Pietrini ${ }^{3}{ }^{[0}$, Giovanni Mele ${ }^{1}$, Donato Giannino ${ }^{1}$ and \\ Giovanna Frugis 1,*(D) \\ 1 Istituto di Biologia e Biotecnologia Agraria (IBBA), Operative Unit of Rome, Consiglio Nazionale delle \\ Ricerche (CNR), Via Salaria Km. 29,300, 00015 Monterotondo Scalo (Roma), Italy; giulio.testone@cnr.it (G.T.); \\ elena.baldoni@cnr.it (E.B.); mariaadelaide.iannelli@cnr.it (M.A.I.); chiara.nicolodi@cnr.it (C.N.); \\ edg75@tiscali.it (E.D.G.); giovanni.mele@cnr.it (G.M.); donato.giannino@cnr.it (D.G.) \\ 2 Istituto di Biologia e Biotecnologia Agraria (IBBA), Consiglio Nazionale delle Ricerche (CNR), Via Bassini 15, \\ 20133 Milano, Italy \\ 3 Istituto di Ricerca sugli Ecosistemi Terrestri (IRET), Operative Unit of Rome, Consiglio Nazionale delle \\ Ricerche (CNR), Via Salaria Km 29,300, 00015 Monterotondo Scalo (Roma), Italy; fabrizio.pietrini@cnr.it \\ * Correspondence: giovanna.frugis@cnr.it; Tel.: +39-06-9067-2889 \\ + These authors equally contributed to this work.
}

Received: 22 October 2019; Accepted: 15 November 2019; Published: 21 November 2019

\begin{abstract}
Cichorium endivia is a leafy crop closely related to Lactuca sativa that comprises two major botanical varieties characterized by a high degree of intraspecific morphological variation: var. latifolium with broad leaves (escarole) and var. crispum with narrow crisp curly leaves (endive). To investigate the relationship between leaf morphology and photosynthetic activity, escaroles and endives were used as a crop model due to the striking morphological diversity of their leaves. We constructed a leaf database for transcription factors (TFs) and photosynthesis-related genes from a refined C. endivia transcriptome and used RNA-seq transcriptomic data from leaves of four commercial endive and escarole cultivars to explore transcription factor regulatory networks. Cluster and gene co-expression network (GCN) analyses identified two main anticorrelated modules that control photosynthesis. Analysis of the GCN network topological properties identified known and novel hub genes controlling photosynthesis, and candidate developmental genes at the boundaries between shape and function. Differential expression analysis between broad and curly leaves suggested three novel TFs putatively involved in leaf shape diversity. Physiological analysis of the photosynthesis properties and gene expression studies on broad and curly leaves provided new insights into the relationship between leaf shape and function.
\end{abstract}

Keywords: transcription factors; photosynthesis; leaf shape; plant development; Cichorium endivia; RNA-seq; cluster analysis; gene co-expression networks

\section{Introduction}

Plant growth and development are critically controlled by light. Photosynthesis is the most important light-dependent process, involving the transduction of photons absorbed by photosynthetic pigments into chemical free energy. Due to the close relationship between net photosynthesis and crop yield, enhancing photosynthetic efficiency constitutes a major target to improve crop production in a global changing climate [1]. 
Leaf morphological differences at inter- and intraspecific level can explain substantial variations in photosynthetic properties under different environmental constraints [2,3]. Thus, the inseparable relationship between leaf architecture and photosynthesis holds great potential to enhance photosynthetic efficiency by modifying leaf anatomy and morphology [1].

Photosynthesis is the consequence of a multistep and complex process that involves several biological pathways, and in particular: (i) the photosynthetic electron transport system (PET), in which the light energy is converted into ATP and NADPH; (ii) the Calvin-Benson cycle, a photosynthetic carbon fixation cycle in which $\mathrm{CO}_{2}$ is fixed into carbohydrates [4,5]. The photosynthetic process is mediated by the coordinated action of ca. 3000 different proteins, commonly referred to as photosynthesis proteins, that are encoded from both chloroplast and nuclear genomes [6,7]. Coordinating the transcription of photosynthesis-associated nuclear genes (PhANGs) and photosynthesis-associated plastid-encoded genes (PhAPGs) to maintain the right balance among nuclear encoded proteins, plastid proteins, carotenoids, and chlorophylls is critical for the correct assembly of functional photoprotective and photosynthetic complexes within chloroplasts under both optimal and suboptimal conditions [8]. A central role in the activation of photosynthesis-related genes is played by the red and far-red light-sensing phytochrome (PHY) family members $[9,10]$. PHYs regulate many aspects of plant growth and development in response to red and far-red light signals from the environment [11]. They are encoded in higher plants by small gene families, for example, Arabidopsis thaliana contains a PHY gene family with five members, with designations from PHYA to PHYE. Phytochromes induce major changes in the expression of genes related to different pathways, including the promotion of the photosynthetic apparatus assembly, and the production of the photosynthetic pigments, chlorophylls, and carotenoids [12-14]. In Arabidopsis thaliana, many transcription factors (TFs) have been identified to be downstream of PHY signaling [8]. Among them, the best characterized are the PHYTOCHROME INTERACTING FACTOR (PIF) and PIFLIKE (PIL) families of basic helix-loop-helix (bHLH) TFs that act mainly as negative regulators of photosynthesis gene expression in response to light availability [8]. PHYs promote the stability of TFs that regulate photosynthesis gene expression, such as ELONGATED HYPOCOTYL 5 (HY5) and HY5-HOMOLOGOUS (HYH) that promote photosynthetic machinery assembly, photopigment production, chloroplast development, and seedling cotyledon expansion [15]. For a broad range of responses, PIFs act antagonistically with HY5 and repress carotenoid accumulation by down-regulating the expression of the PHYTOENE SYNTHASE (PSY) gene, the main rate-determining enzyme in the carotenoid pathway [16]. PHY-mediated PIF degradation is a central mechanism for inducing chloroplast biogenesis through the activation of specific PhANGs [17] such as GOLDEN2-LIKE (GLK), SIGMA FACTORS (SIG), and GROWTH REGULATING FACTORS (GRF) [18]. GLKs positively regulate chloroplast development and the expression of photosynthesis genes like those encoding light-harvesting complex (LHC) proteins and key enzymes of the chlorophyll biosynthetic pathway. The nuclear encoded SIGs activate the plastid-encoded RNA polymerase (PEP) that drives the expression of plastid-encoded genes for photosynthesis proteins, including core components of photosystem I (PSI) and photosystem II (PSII) [8]. GRFs regulate chloroplast division and represent an important link between photosynthesis and leaf growth. In fact, GRFs and their interacting factors (GIFs) control growth and development of leaves and cotyledons by regulating meristem function through the control of cell proliferation [19]. Plastid signals repress the induction of light-induced genes through plastid-to-nucleus retrograde signals emitted by dysfunctional chloroplasts (retrograde signaling, RS) $[18,20,21]$. Phytochrome and RS pathways converge antagonistically to regulate the expression of GLK1, i.e., normal light lead to the induction of the GLK1 regulator whereas light at excessive levels is sensed by the plastid leading to GLK1 repression [22].

Although the function of many photosynthetic genes is known, the dissection of the genetic networks underlying photosynthesis gene expression is challenging as they are interconnected with those that control other plant developmental and biochemical processes. Despite this complexity, about 70 transcriptional regulators which alter the expression of groups of photosynthesis genes or the photosynthetic activity in Arabidopsis have been identified [8]. The small size of this regulatory 
network indicates that several key players are yet to be known. Unraveling this complex regulatory network is, thus, crucial for the development of strategies for increasing photosynthetic efficiency, as well as identifying the role and importance of leaf shape in contributing to the photosynthetic output of leaves, which is largely unexplored. Whereas some studies on the relationship between leaf anatomy (i.e., chloroplast number, mesophyll cell size, and morphology) and leaf photosynthetic capacity are available [1], those dealing with the relationship between photosynthesis and leaf shape are quite limited. One study was carried out on Pelargoniums and highlighted a correlation between the degree of leaf dissection and the photosynthetic rates under a high temperature [23]. A recent work used both idealized and scanned leaves from Arabidopsis and Cardamine hirsuta to test whether the phyllotaxis Fibonacci golden angle was optimal for light capture [24], but no relationship with photosynthesis efficiency was analyzed.

To investigate the relationship between leaf morphology and photosynthetic activity, we studied four Cichorium endivia cultivars belonging to the two major botanical varieties characterized by a high degree of intraspecific leaf morphological variation, var. latifolium with broad leaves (escarole) and var. crispum with narrow crisp curly leaves (endive). We used a C. endivia transcriptome and RNA-seq data from leaves of escaroles and endives to obtain a bona fide leaf database of transcription factors and photosynthesis-related genes. Cluster analysis and construction of gene co-expression networks (GCN) allowed the identification of a main photosynthesis-driven TF regulatory network with a central role in the leaf transcriptome, as well as candidate genetic hubs controlling the overall leaf transcriptional network. Morphological and physiological analysis of photosynthetic parameters were carried out to establish a possible link between photosynthesis and leaf shape. Differential expression analysis between broad- and curly-leaved plants, and a "guilt by association" approach within gene co-expression networks identified developmental genes that may play a role at the boundary between photosynthesis and leaf shape.

\section{Results}

\subsection{Construction of TF-PHOTO, a C. Endivia Leaf Database for Transcription Factors and Photosynthesis-Related Genes}

We used the transcriptome of C. endivia (cv 'Domari'), previously obtained in our lab by de novo assembly [25], and leaf RNA-seq data from two production cycles, to construct a bona fide leaf database of transcription factors and photosynthesis-related genes (TF-PHOTO) (Table S1). First, a previous raw TF database [25], based on the TF prediction server of the PlantTFDB [26], was refined to obtain a reliable novel database including only non-redundant full-length and near full-length TF transcripts. To achieve this, the database was implemented by integrating homologues of Lactuca sativa TFs recently annotated in the PlantTFDB platform or published [27]. All the contigs (ca 6000) were then: (i) aligned to the released L. sativa genome [28] to obtain 0 to 1 hint/locus (Table S2), (ii) filtered for full-length percentage prediction (FL\%) $\geq 0.7$ in protein-protein alignment with lettuce peptide database, (iii) validated as TFs with the MapMan package [29], and (iv) filtered for leaf expression in more than $90 \%$ of the RNA-seq leaf samples. Genes homologous to those involved in the transcriptional control of photosynthesis [8] were also identified in C. endivia and integrated in the database if not present. A total of 1560 bona fide unigenes were finally obtained, which were assigned to families according to the PlantTFDB rules [26] (Figure 1).

As for photosynthesis and photosynthesis-related genes (energy dissipation and reactive oxygen species detoxification) homologues of Arabidopsis thaliana genes belonging to GO:0015979 (photosynthesis), GO:0009813 (flavonoid metabolic processes), GO:0016116 (carotenoid metabolic process), and GO:0019852 (ascorbic acid metabolic process) terms were identified. These contigs were also aligned to L. sativa genome, filtered for expression in leaves, and added to the final TF-PHOTO database that contained a total of 1833 genes (Table S1). 


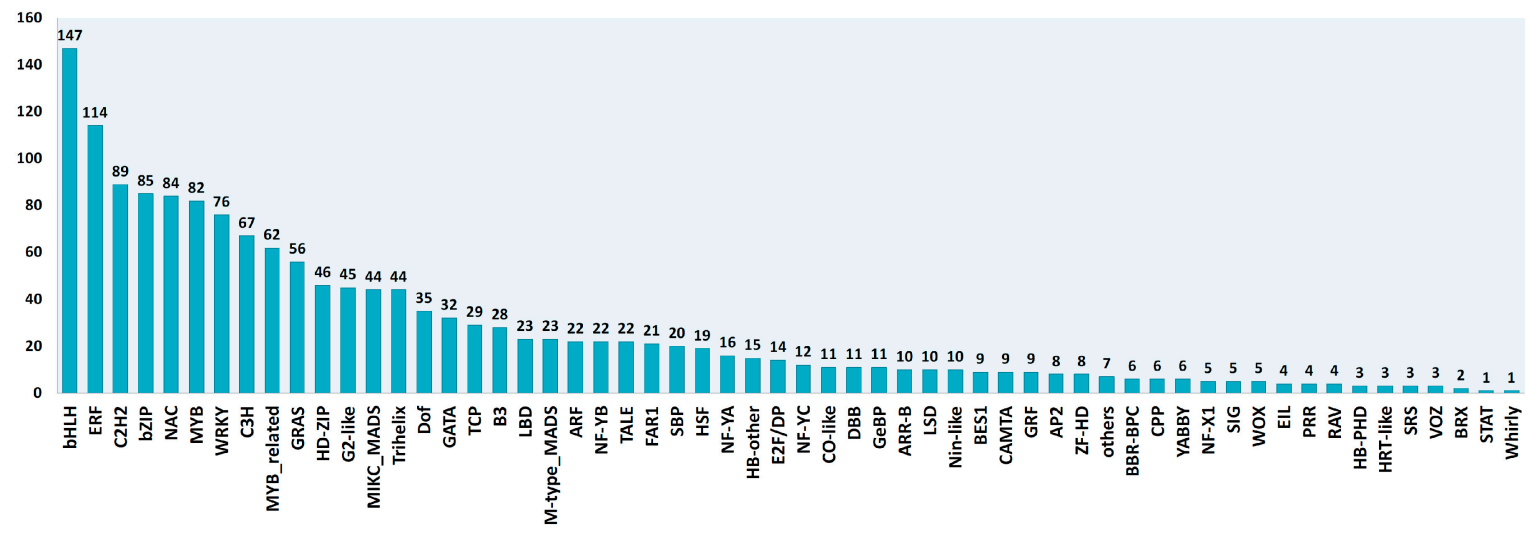

Figure 1. Identification and assignment of the 1560 transcription factors (TFs) expressed in the leaves of C. endivia according to the PlantTFDB rules [26].

\subsection{Finding Expression Patterns in Leaves Using K-Means Cluster Analysis}

To characterize the regulatory transcriptional networks occurring in mature leaves, we analyzed RNA-seq data from leaves of field-grown plants of four commercial cultivars of $C$. endivia, the curled-leaved endives 'Domari' and 'Myrna' and the broad-leaved escaroles 'Confiance' and 'Flester', obtained from two independent years of production, 2011 (previously unpublished) and 2012 [25]. To identify groups of genes with similar expression profiles within our TF-PHOTO database, we performed K-means clustering [30], which uses Euclidean or correlation distance as similarity measures [31]. As K-means clustering requires a priori knowledge of the number of clusters, we tested several methods and empirically established the optimum number at eight using an a posteriori validation method (Figures S1-S3). The results of the K-means analysis are shown in Figure 2a-h. Amongst the eight clusters, cluster three (Figure 2c) contained most of the genes directly related to photosynthesis (Figure 2i, Table S1) and was highly anticorrelated with cluster six $(r=-0.97)$ (Figure 2f, Figure S4), which likely contained negative regulators of photosynthesis or antagonistic pathways. Cluster three and six represented the two most abundant and robust clusters (465 and 281 genes, medium correlation index with centroid $=0.87$ and 0.86 , respectively), which reflects the major function of leaves as photosynthetic organs. The gene expression profiles in cluster three and six pointed to a different behavior of 'Flester' with respect to the other three cultivars. 'Domari', 'Myrna', and 'Confiance' showed a strong difference in gene expression levels between the two years of production (2011 and 2012), whereas 'Flester' displayed similar expression levels in the two years (Figure 2c,f). Photosynthesis-related genes were generally expressed at lower levels in 'Flester' as compared with the other cultivars, particularly in 2011 samples. As for the other clusters, cluster five and seven (Figure 2e,g) were the least abundant and most heterogeneous, with several genes showing low correlation with the cluster core (black thick line in Figure 2). Instead, cluster one, two, and eight represented several genes that fit well with cluster assignment, with most genes showing high correlation indexes with the cluster core (Table S1). Cluster one and eight (Figure 2a,h) were mildly correlated to cluster three, whereas cluster two displayed a mild similarity to cluster six (Figure 2b,f, Figure S4). Calculating how closely a gene matches the cluster core/centroid, helps identify genes that might play a role in determining the expression of the cluster as a whole [31]. For cluster three and six, a gene homologous to the Arabidopsis PIF1/PIL5 (Ce_contig26819/CebHLH_64) and a gene homolog to the Arabidopsis bZIP17 (Ce_contig46896/CebZIP_41), respectively, were the closest to the core (Table S1). These genes may have a prominent role in regulating gene expression in cluster three and six.

This analysis successfully identified the main gene regulatory network of photosynthesis in C. endivia leaves, that included homologues of several known transcriptional regulators of the photosynthetic process such as PHYB, HY5/HYH, PIFs, GLKs, GRFs, and SIGs [8]. PHYE and PHYA were found in cluster three but with lower scores to core ( 0.83 and 0.69 , respectively) (Table S1). A 
prominent role of $C e b H L H \_64$ and CebZIP_41 as master regulators of the photosynthetic transcriptional network in C. endivia leaves can be hypothesized based on their closeness to the respective cluster cores.

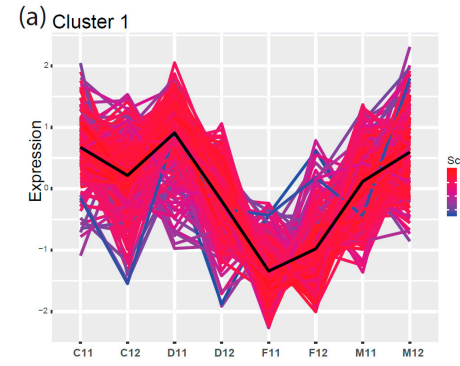

(d) Cluster 4

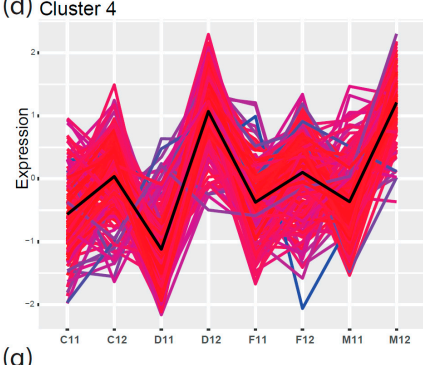

(g) Cluster 7

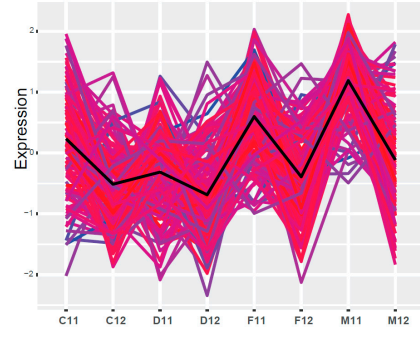

(b) Cluster 2

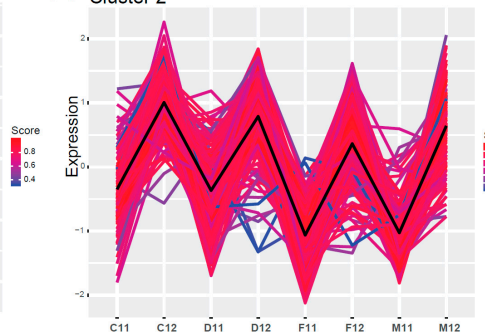

(e) Cluster 5

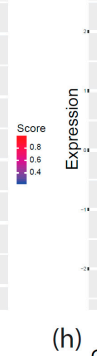

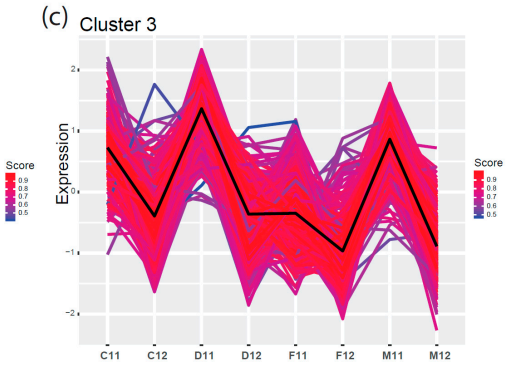

(f) Cluster 6

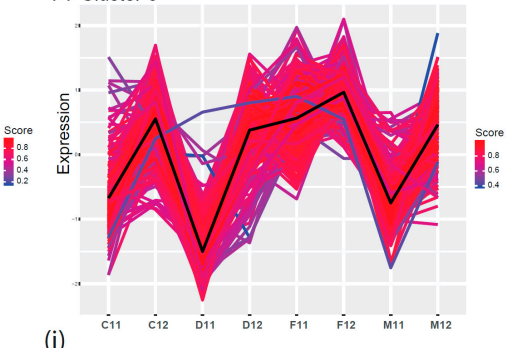

(i)

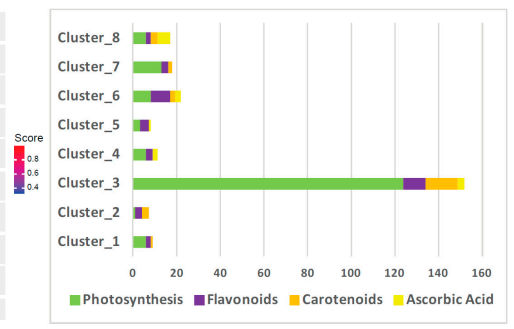

Figure 2. K-means cluster analysis of TF-PHOTO gene expression in the leaves of field-grown endives and escaroles for two production cycles (from 2011 to 2012). Distance matrix for k-mean clustering was calculated by Euclidean similarity measurement and using centered Pearson's correlation as the distance metric, resulting in eight gene clusters $(\mathbf{a}-\mathbf{h})$. Genes with a profile close to the core have a score approaching one (red) while those with divergent patterns have a score closer to zero (blue). Thick lines show centroid tendencies in each cluster according to cultivar and production year. C, Confiance; D, Domari; F, Flester; and M, Myrna. Cluster three (c) contains most of the genes directly related to photosynthesis and is highly anticorrelated with cluster six $(\mathbf{f})(r=-0.97)$ which likely contains negative regulators of photosynthesis or antagonistic pathways. (i) Graphical visualization of enrichment results and gene characteristics according to gene ontology (GO) functional categories.

However, the presence of a homologue of the Arabidopsis PIF1/PIL5 as a main positive driver of gene expression in cluster three was unexpected as PIF1/PIL5 is a key negative regulator of phytochrome-mediated responses, and acts by inhibiting chlorophyll biosynthesis [32]. In our database, another two homologues of PIF1/PIL5 are present in cluster six and cluster eight, indicating that they may have retained the function of Arabidopsis PIF1/PIL5, whereas CebHLH_64 may have acquired a different function in C. endivia. A homologue of PIF3 was also present in cluster eight, which contains genes whose expression levels remained constant during the two years of production, although always lower in 'Flester' as compared with the other three cultivars.

\subsection{Analysis of Gene Co-expression Networks of C. endivia Leaves}

To provide a global overview of co-expression patterns of the C. endivia TF-PHOTO genes, we used a total of 23 RNA-seq samples from the two independent field experiments to construct a targeted 
gene co-expression network (GCN). The workflow used to obtain and analyze the GCN is shown in Figure 3.

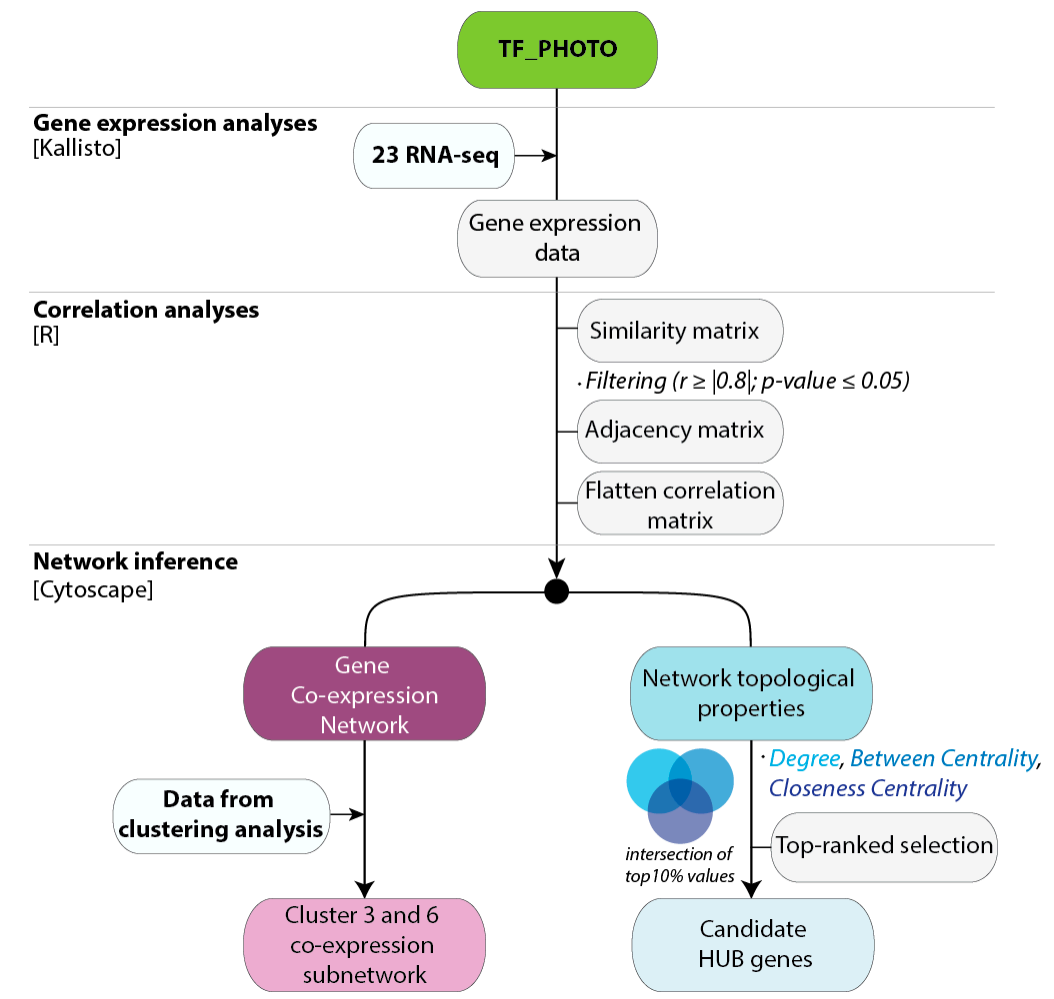

Figure 3. Workflow used to generate the gene co-expression Networks for the TF-PHOTO database. All the information about the database, including sequences, annotations, and the original RPKM data used for the analyses is available in Table S1. The flatten matrices of the pairwise correlation data for $\mathrm{r}$ $\geq|0.8|$ and $r \geq|0.9|$ are in Table S3 and can be directly used to feed Cytoscape.

We performed pairwise correlation analysis on TF-PHOTO gene expression values, and used significant and very strong positive and negative correlations $(r \geq|0.8|)$ to construct the network (Table S3), that was then visualized and explored with Cytoscape [33] (Figure 4). Out of 1833 TF-PHOTO genes, 1406 formed a major tight network with a clustering coefficient of 0.542 and a characteristic path length of three (Figure $4 \mathrm{a}$ ). The clustering coefficient is a measure of the degree to which nodes in a graph tend to cluster together and varies from zero to one, with zero meaning no connections and one meaning all possible connections [33]. The characteristic path length is a measure of the efficiency of information flow on a network that indicates the average number of steps along the shortest paths for all possible pairs of network nodes, the lower the number the easier the communication [33]. According to these parameters, our network is formed by highly interconnected genes that easily communicate information to each other.

In graph theory, centrality provides a means of ranking nodes based on network structure. To identify key components (hubs) in the network, we ranked the genes according to the following three important centrality parameters: (i) node degree, which is the number of neighbors to which a node directly connects; (ii) closeness centrality, which estimates how fast the flow of information would be through a given node to other nodes; and (iii) betweenness centrality, which defines the number of information streams passing through a given node [34]. Using these centrality parameters, 10 top-ranked hub genes (highlighted in pink in Table S4 and Table S1) were identified as those with percentile ranking of 10 (top 10\%) of node degree, betweenness centrality and closeness centrality indexes. All the 10 hub genes belonged to either cluster three or cluster six, and included homologues of known regulators of photosynthesis such as sigma factors and 
cytokinin response regulators that mediate light effect on chlorophyll concentration [35]. Interestingly, three homologues of Arabidopsis ETHYLENE-RESPONSIVE TRANSCRIPTION FACTORS (ERFS) (Ce_contig59871/ERF_80; Ce_contig147/ERF_1; Ce_contig85235/ERF_106), one of AUXIN RESPONSE FACTOR 9 (Ce_contig36168/ARF_9) and one of the MANNOSE-6-PHOSPHATE ISOMERASE 1 (Ce_contig50113/PMI2) involved in ascorbic acid biosynthesis, resulted to play a central role in the photosynthesis transcriptional regulatory network and constitute novel potential players in this process. Within the GCN, a homologue of the Arabidopsis MYB73 TF (Ce_contig73456/MYB_58) had the highest number of connections and can be also considered an important hub in the network (Table S4). Figure $4 \mathrm{~b}$ shows the GCN subnetwork formed by cluster three and cluster six genes, which constitutes the core of the TF-PHOTO main global network. The antagonistic relationship between genes of cluster three and those of cluster six is central in the network, and mildly influences also genes belonging to cluster one, two and seven. This is shown by the medium-high degrees of centroid-centroid correlation of cluster one, two and seven with cluster three and six, and by the existence of two main anticorrelated blocks of TF-PHOTO transcript expression (Figures S3 and S4).

(a)

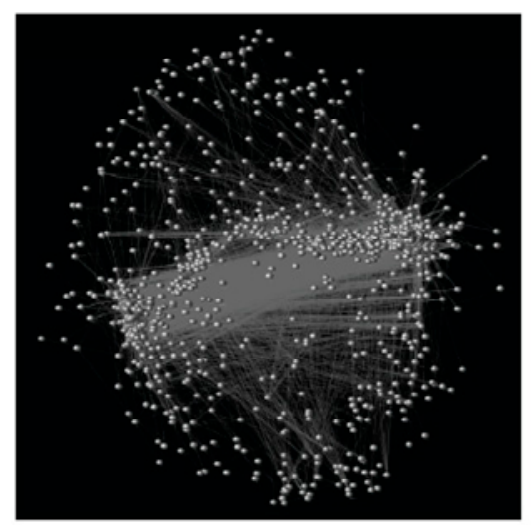

\section{GCN_1406 parameters}

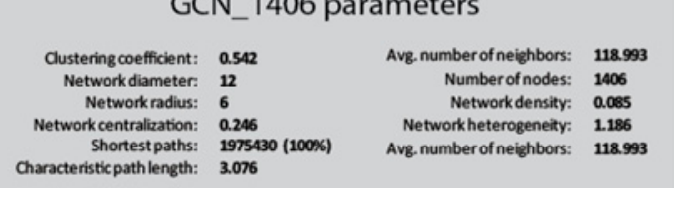

(b)

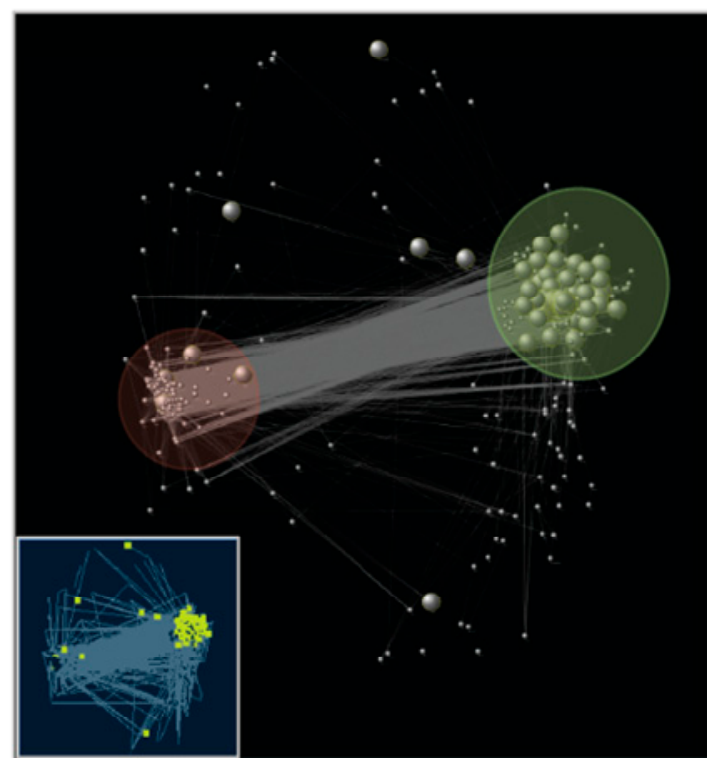

Figure 4. Gene co-expression network identified for the TF-PHOTO genes. (a) Global co-expression network and GCN parameters, grey vertices (genes) are connected by an edge if a predefined association between vertices pairs is determined and (b) cluster three (in the light green circle) and cluster six (in the light red circle) subnetworks. Bigger grey dots in the big picture, and yellow dots in the smaller picture, represent photosynthesis pathway genes at the core of the TF-PHOTO main global network.

Overall, GCN data were consistent with the cluster analysis and pointed to the existence of a main photosynthesis-driven TF regulatory network that plays a central role in the leaf transcriptome.

\subsection{Interplay Between Shape and Function: Photosynthetic Parameters in Relation to Morphological Leaf Diversity}

C. endivia escaroles and endives represent a good model to study the relationship between leaf shape and photosynthetic activity as they are characterized by a high degree of intraspecific morphological variation (Figure 5i). 

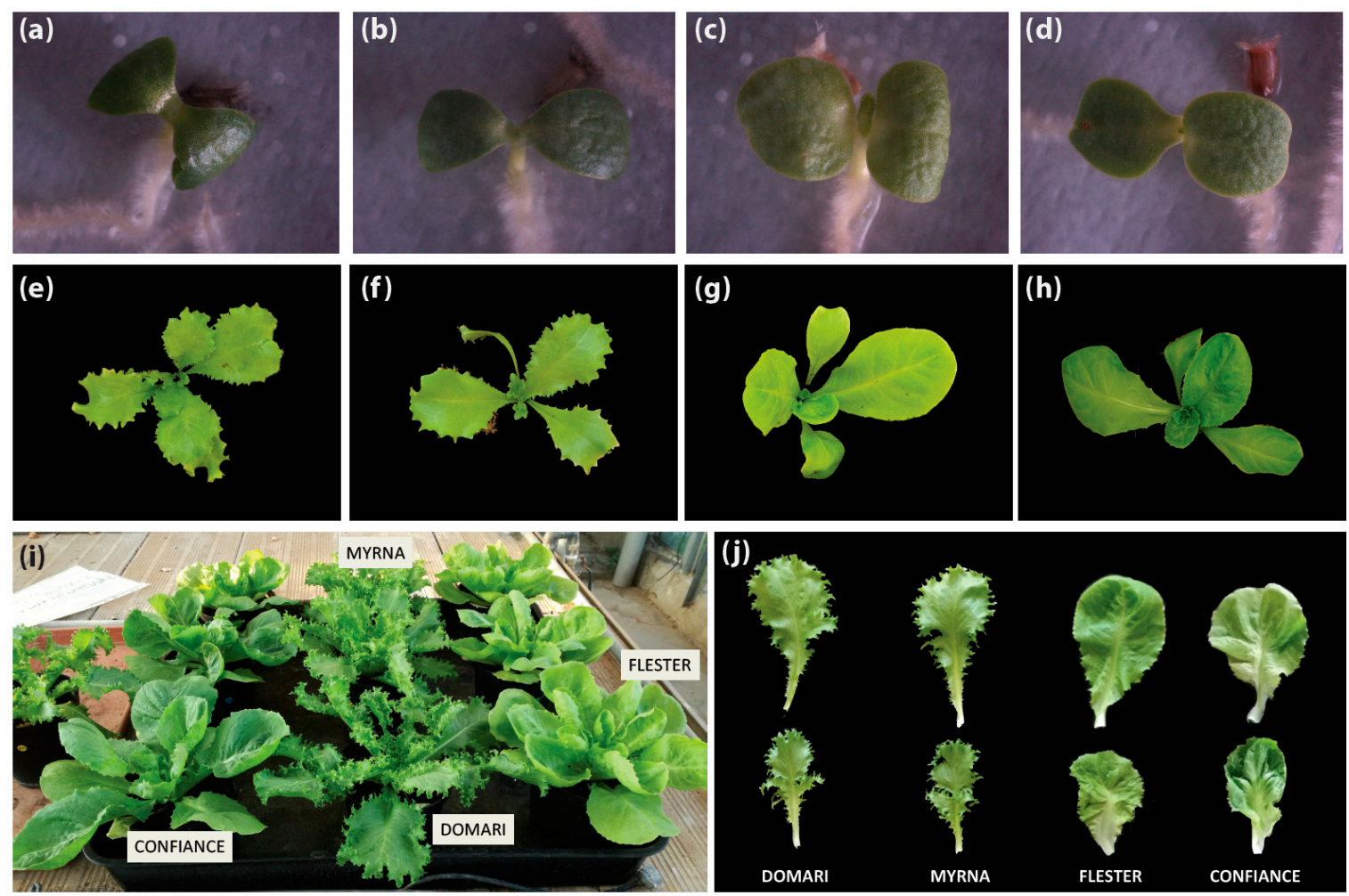

(k)

(I)
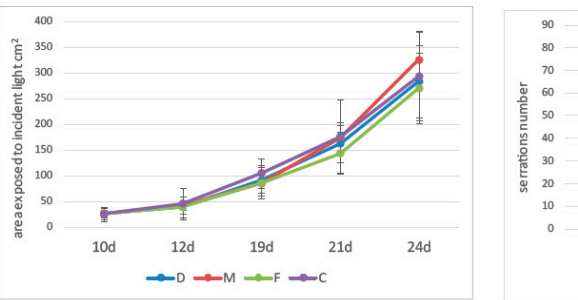

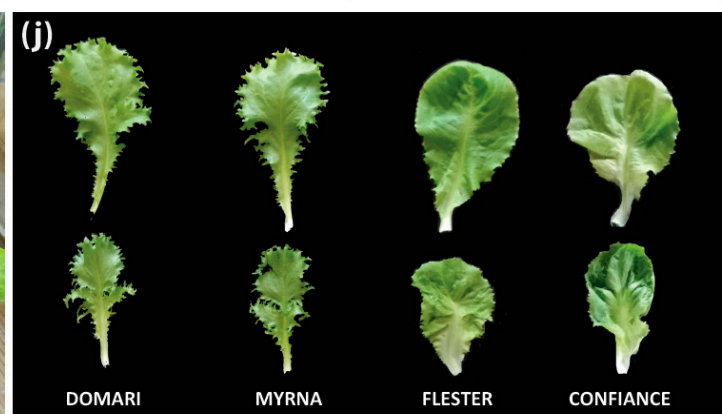

(m)

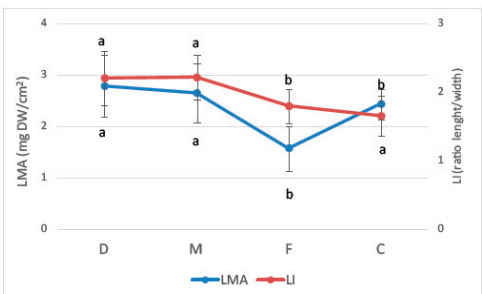

Figure 5. Morphological analysis of C. endivia endives, 'Domari' (a,e,i,j) and 'Myrna' $(\mathbf{b}, \mathbf{f}, \mathbf{i}, \mathbf{j})$, and escaroles, 'Flester' (c, $\mathbf{g}, \mathbf{i}, \mathbf{j})$ and 'Confiance' $(\mathbf{d}, \mathbf{h}, \mathbf{i}, \mathbf{j})$. (a-d) Cotyledonary stage, (e-h) 20-day-old plantlets, (i) 40-day-old endive and escarole plants, (j) 20th leaf of 50 days mature endive and escarole plants, and (k) plant area exposed to incident light in 10- to 24-day-old endive and escarole plantlets (mean \pm SD, $n$ =6). Means with different letters represent significant difference at $p<0.05$. (1) Number of serrations on the first, second, and third leaves in endives and escarole 21-day-old plantlets (mean $\pm \mathrm{SD}, n=6$ ). Means with different letters represent significant difference at $p<0.05$. (m) Ratio of leaf dry mass to leaf area (LMA) and ratio of leaf length to leaf width (LI) in fully expanded leaves of 50-day-old endive and escarole plants (mean \pm SD, $n=6$ ). D, Domari; M, Myrna; F, Flester; C, Confiance.

The 'Confiance' and 'Flester' escaroles have broad leaves as compared with 'Domari' and 'Myrna' endives that develop narrow crisp curly leaves (Figure 5j). Differences between escarole and endive development are visible since the cotyledonary stage, as cotyledons are large and rounded in 'Confiance' and 'Flester' (Figure 5c,d) and more elongated and narrow in 'Domari' and 'Myrna' (Figure 5a,b). The leaves of endives are elongated and develop serrations from the first leaf onwards, whose number exponentially increases in subsequent leaves (Figure $5 \mathrm{e}, \mathrm{f}$ ), until they become deeply lobed or even dissected at the mature stage (Figure 5j). Differently, leaves of escaroles are rounded and smooth, with few small protrusions, and develop into large leaves with slightly wavy margins (Figure $5 \mathrm{~g}, \mathrm{~h}, \mathrm{j}$ ).

We measured morphological parameters of 'Domari', 'Myrna', 'Flester', and 'Confiance' plants at early stages of development, and analyzed changes in the area exposed to incident light and in the ratio of leaf dry mass to leaf area (LMA). Although leaf shape was considerably different between endives 
and escaroles (leaf length and width expressed as leaf index (LI), number of serrations) (Figure 5l,m), the overall leaf area exposed to incident light did not statistically differ between the two varietal types (Figure 5k). This indicates a compensatory mechanism that allows plants with different leaf shapes to balance their leaf growth rate to optimize interception of light for photosynthesis. Only 'Flester' differed in the LMA parameter, which is a measure of the leaf-level cost of light interception that correlates growth with carbon gain (Figure $5 \mathrm{~m}$ ), suggesting possible differences in leaf structure and anatomy [36].

To evaluate the photosynthetic performance of 'Domari', 'Myrna', 'Flester', and 'Confiance', measurements of chlorophyll fluorescence imaging, leaf chlorophyll content, and photochemical reflectance index were performed (Table 1). A representative image of chlorophyll fluorescence parameters, such as maximal quantum efficiency of PSII photochemistry $\left(\mathrm{F}_{\mathrm{v}} / \mathrm{F}_{\mathrm{m}}\right)$ and quantum efficiency of PSII photochemistry (ФPSII), in leaves of the cultivars used in this experiment is presented in Figure 6. Chlorophyll fluorescence analysis is a rapid nondestructive tool to evaluate the state of the photosynthetic apparatus [37]. Our results showed that the values $F_{v} / F_{m}$ were significantly different among the cultivars (Table 1). Nevertheless, our data highlighted that the values of the Fv/Fm ratio for all cultivars were within the $0.75-0.85$ range, which indicate non-stressed conditions in the plants under study. The $\Phi$ PSII, the most useful parameter to measure the efficiency of PSII photochemistry [38], indicated higher values in 'Confiance' and 'Domari' with respect to 'Myrna' and 'Flester' (Table 1). A similar trend was also detectable for the electron transport rate (ETR) data, confirming the higher photosynthetic performance of 'Confiance' and 'Domari'. 'Flester' had the lowest values of ETR as compared with the other cultivars. In addition, leaf chlorophyll content resulted higher in 'Confiance' and 'Domari' leaves but significantly lower in 'Flester'. Furthermore, the analysis of apparent absorptivity of the leaf surface (Abs) (Table 1) showed a trend similar to chlorophyll content, corroborating a strong correlation between the leaf absorbance and the total chlorophyll content in all the cultivars analyzed. The higher photosynthetic performance for 'Confiance' and 'Domari' was confirmed through photochemical reflectance index (PRI) measurements, where PRI is a spectral index linked to photosynthetic parameters and pigments content in plant [39]. 'Flester' plants showed a significant lower PRI index (Table 1).

Table 1. Chlorophyll fluorescence parameters of the four C. endivia cultivars.

\begin{tabular}{|c|c|c|c|c|c|c|}
\hline Cultivar & \multicolumn{6}{|c|}{ Parameters $^{1}$} \\
\hline Domari & $0.793 \pm 0.001 \mathrm{c}$ & $0.405 \pm 0.004 b$ & $55.73 \pm 0.53 b$ & $0.746 \pm 0.006 \mathrm{~b}$ & $19.87 \pm 0.96 b$ & $0.043 \pm 0.001 \mathrm{a}$ \\
\hline Myrna & $0.807 \pm 0.001 b$ & $0.375 \pm 0.003 c$ & $49.42 \pm 0.47 c$ & $0.715 \pm 0.002 c$ & $17.25 \pm 1.98 \mathrm{bc}$ & $0.038 \pm 0.001 \mathrm{ab}$ \\
\hline Flester & $0.828 \pm 0.001 \mathrm{a}$ & $0.375 \pm 0.003 c$ & $46.64 \pm 0.47 \mathrm{~d}$ & $0.675 \pm 0.009 \mathrm{~d}$ & $14.51 \pm 1.01 \mathrm{c}$ & $0.033 \pm 0.001 b$ \\
\hline
\end{tabular}

${ }^{1}$ Chlorophyll fluorescence parameters measured in leaves of endives (cv 'Domari' and 'Myrna') and escaroles (cv 'Flester' and 'Confiance') cultivars. $\mathrm{F}_{\mathrm{v}} / \mathrm{F}_{\mathrm{m}}$, maximal quantum efficiency; $\Phi$ PSII, quantum efficiency of PSII photochemistry; ETR, electron transport rate; Abs, photosynthetically active radiation absorptivity; and PRI, photochemical reflectance index (PRI). Different letters in the same column indicate significant differences $(p \leq 0.05)$ according to ANOVA analysis. 


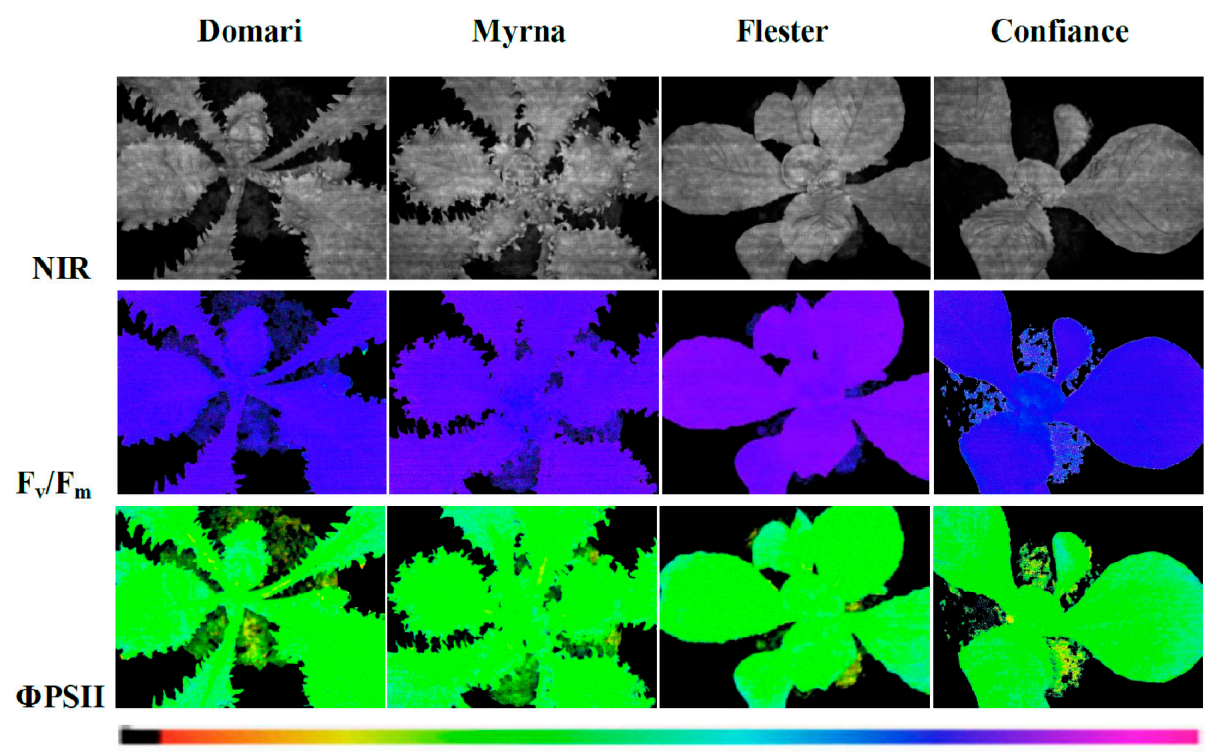

Figure 6. Images of chlorophyll fluorescence parameters in leaves of endives (cv 'Domari' and 'Myrna') and escaroles (cv 'Flester' and 'Confiance') cultivars grown under greenhouse conditions. Near-infrared images (NIR) of representative leaves, maximal quantum efficiency $\left(\mathrm{F}_{\mathrm{v}} / \mathrm{F}_{\mathrm{m}}\right)$ measured in dark adapted leaves and quantum efficiency of PSII photochemistry ( $\Phi$ PSII) measured at steady state with light intensity of $370 \mu \mathrm{mol}$ photons $\mathrm{m}^{-2} \mathrm{~s}^{-1}$ are shown using an Imaging-PAM M-series system. The false colour code depicted at the bottom of the images ranges from 0.000 (black) to 1.000 (pink).

In order to study the relationship between the leaf shape and the photosynthetic activity and to evaluate the spatial heterogeneity of the photosynthetic activity on the leaf surface, on the chlorophyll fluorescence images (Figure 6), four area of interested (AOI), two in the central part of the leaf (internal) and two in the outer zones (external), were selected. Data reported in Table S5 show that, inside of each cultivar, no difference between values of $\mathrm{F}_{\mathrm{v}} / \mathrm{F}_{\mathrm{m}}$ and $\Phi$ PSII measured in the internal and external areas was found. These findings suggest that, in our experimental conditions, leaf shape did not modify the photosynthetic efficiency over the leaf surface.

In order to evaluate the response of 'Flester' cultivar regarding its reduced photosynthetic performance we also measured carotenoid and malondialdehyde (MDA) contents (Figure S5). Carotenoids act as light harvesters, quenchers and scavengers of triplet state chlorophylls, and singlet oxygen species, dissipators of excess harmful energy during stress condition and membrane stabilizers [40]. MDA is produced from the lipid peroxidation of polyunsaturated fatty acid (PUFAs) in response to oxidative stress by ROS attack [41] but it has recently been suggested that MDA may act as a protection mechanism rather than being a damage indicator if the elimination of MDA and redox signaling regulation works correctly [41]. The 'Flester' cultivar showed a significant reduction of carotenoids and increased amount of MDA (Figure S5). These results are consistent with the physiological parameters and the altered expression of genes related to photosynthesis observed in the 'Flester' cultivar (Figure 7). In conclusion, in our experimental conditions the major alterations in the photosynthetic properties were due to the different cultivar genotypes, whereas no significant differences were linked to the two morphological phenotypes of endives and escaroles. 
(a) Light response
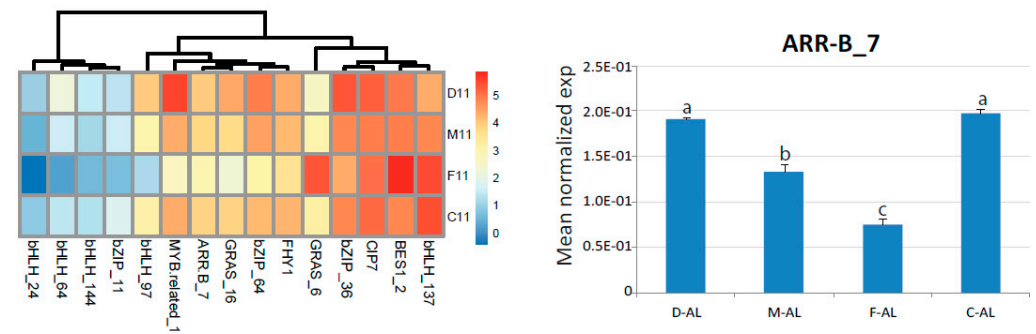

(b) Master regulators
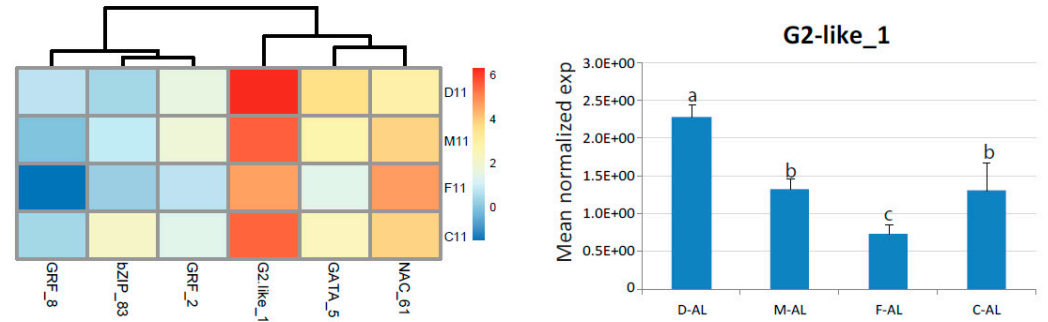

(c) Chloroplast response
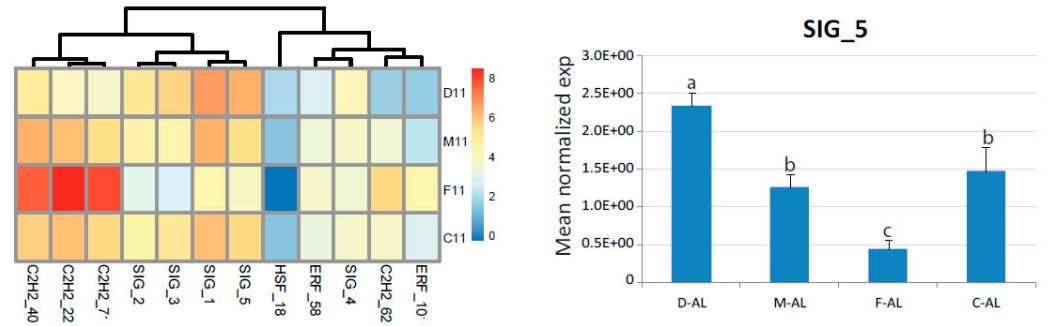

(d) Downstream genes
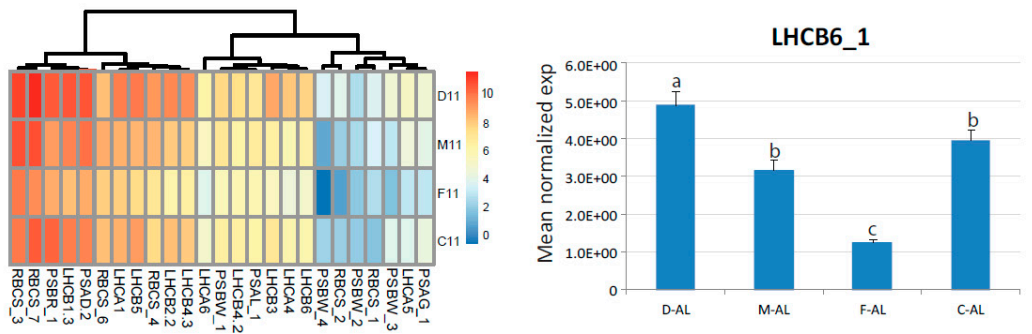

Figure 7. Heat map showing relative expression values (log2 RPKM) of genes differentially expressed in endive and escarole cultivars (year 2011) and related to photosynthesis: (a) Light response genes; (b) master regulators genes; (c) chloroplast response genes; and (d) downstream genes ( $L H C B, R B C$, photosystems). The expression of one gene for category was reconfirmed by qRT-PCR on RNA from mature leaves (AL). D, 'Domari'; M, 'Myrna'; F, 'Flester'; and C, 'Confiance'.

\subsection{Interplay Between Development and Function: Developmental Genes Related to the Photosynthetic} Regulatory Pathway

In order to explore a possible link between the photosynthetic regulatory network and leaf development, we searched the cluster three and six modules for genes involved in developmental processes (GO:0044767). We found a total of 191 genes, of which 110 were in cluster three and 81 were in cluster six. Amongst developmental genes, we identified those that were positioned very close to the clusters core (score to core close to one) (Table 2). 
Table 2. List of developmental genes of interest found in cluster three and six that were selected amongst those having a high score to core. Known genes involved in photosynthesis regulations are in green.

\begin{tabular}{|c|c|c|c|c|c|c|}
\hline Ce ID & Category & Ath ID & Gene Symbol & Score to Core & $\mathrm{K}$ & Ce Gene Name \\
\hline Ce_contig37589 & $\mathrm{TF}$ & AT4G30080 & AUXIN RESPONSE FACTOR 16 (ARF16) & 0.925 & 3 & ARF_11 \\
\hline Ce_contig68433 & $\mathrm{TF}$ & AT2G25180 & RESPONSE REGULATOR 12 (RR12) & 0.964 & 3 & ARR-B_7 \\
\hline Ce_contig18469 & TF & AT1G14920 & GIBBERELLIC ACID INSENSITIVE (GAI) & 0.936 & 3 & GRAS_16 \\
\hline Ce_contig31926 & $\mathrm{TF}$ & AT5G17490 & RGA-LIKE PROTEIN 3 (RGL3) & 0.972 & 3 & GRAS_23 \\
\hline Ce_contig82634 & TF & AT4G00150 & LOST MERISTEMS 3 (LOM3/SCL6-IV) & 0.918 & 3 & GRAS_43 \\
\hline Ce_contig6575 & $\mathrm{TF}$ & AT4G00150 & LOST MERISTEMS 3 (LOM3/SCL6-IV) & 0.948 & 3 & GRAS_7 \\
\hline Ce_contig71598 & TF & AT3G13960 & GROWTH-REGULATING FACTOR 5 (GRF5) & 0.941 & 3 & GRF_8 \\
\hline Ce_contig83059 & $\mathrm{TF}$ & AT4G32880 & ATHB-8 & 0.933 & 3 & HD-ZIP_ 41 \\
\hline Ce_contig21296 & TF & AT2G22540 & SHORT VEGETATIVE PHASE (SVP) & 0.938 & 3 & MIKC-MADS_10 \\
\hline Ce_contig36777 & $\mathrm{TF}$ & AT5G65060 & MADS AFFECTING FLOWERING 3 (MAF3) & 0.973 & 3 & MIKC-MADS_13 \\
\hline Ce_contig30145 & TF & AT5G60440 & AGAMOUS-LIKE 62 (AGL62) & 0.936 & 3 & Mtype_MADS_10 \\
\hline Ce_contig1183 & TF & AT3G61250 & MYB DOMAIN PROTEIN 17 (MY'B17) & 0.898 & 3 & MYB_2 \\
\hline Ce_contig13510 & РНОТО & AT2G18790 & PHYTOCHROME B (PHYB) & 0.928 & 3 & PHYB \\
\hline Ce_contig73618 & TF & AT2G33810 & SQUAMOSA PROMOTER BINDING PROTEIN-LIKE 3 (SPL3) & 0.899 & 3 & SBP_14 \\
\hline Ce_contig85637 & TF & AT2G36990 & SIGMA FACTOR 6 (SIG6) & 0.955 & 3 & SIG_5 \\
\hline Ce_contig49086 & TF & AT3G27010 & TEOSINTE BRANCHED 1, CYCLOIDEA, PCF (TCP) 20 (TCP20) & 0.908 & 3 & TCP_12 \\
\hline Ce_contig33120 & $\mathrm{TF}$ & AT3G47620 & TEOSINTE BRANCHED, CYCLOIDEA, PCF (TCP) 14 (TCP14) & 0.986 & 3 & TCP_7 \\
\hline Ce_contig38256 & TF & AT1G19850 & MONOPTEROS (MP) & 0.947 & 6 & ARF_12 \\
\hline Ce_contig18795 & $\mathrm{TF}$ & AT1G27730 & SALT TOLERANCE ZINC FINGER (STZ) (ZAT10) & 0.985 & 6 & $\mathrm{C} 2 \mathrm{H} 2-22$ \\
\hline Ce_contig46000 & TF & AT1G27730 & SALT TOLERANCE ZINC FINGER (STZ) (ZAT10) & 0.955 & 6 & $\mathrm{C}_{2} \mathrm{H}_{2} 40$ \\
\hline Ce_contig76425 & $\mathrm{TF}$ & AT1G27730 & SALT TOLERANCE ZINC FINGER (STZ) (ZAT10) & 0.967 & 6 & $\mathrm{C}_{2} \mathrm{H}_{2}-62$ \\
\hline Ce_contig81969 & TF & AT1G27730 & SALT TOLERANCE ZINC FINGER (STZ) (ZAT10) & 0.988 & 6 & $\mathrm{C}_{2} \mathrm{H}_{2}-71$ \\
\hline Ce_contig56990 & $\mathrm{TF}$ & AT4G34410 & REDOX RESPONSIVE TRANSCRIPTION FACTOR 1 (RRTF1) & 0.976 & 6 & ERF_75 \\
\hline Ce_contig5939 & TF & AT5G48150 & PHYTOCHROME A SIGNAL TRANSDUCTION 1 (PAT1) & 0.946 & 6 & GRAS_6 \\
\hline Ce_contig26571 & $\mathrm{TF}$ & AT4G37740 & GROWTH-REGULATING FACTOR 2 (GRF2) & 0.954 & 6 & GRF_1 \\
\hline Ce_contig19510 & $\mathrm{TF}$ & AT5G66870 & ASYMMETRIC LEAVES 2-LIKE 1 (ASL1) & 0.934 & 6 & LBD_6 \\
\hline Ce_contig49004 & $\mathrm{TF}$ & AT4G21440 & MYB-LIKE 102 (MYB102) & 0.974 & 6 & MYB_36 \\
\hline Ce_contig8173 & TF & AT2G31180 & MYB DOMAIN PROTEIN 14 (MYB14) & 0.945 & 6 & MYB_9 \\
\hline Ce_contig7 & $\mathrm{TF}$ & AT3G10500 & NAC DOMAIN CONTAINING PROTEIN 53 (NAC053) & 0.971 & 6 & NAC_1 \\
\hline Ce_contig47321 & $\mathrm{TF}$ & AT5G13180 & VND-INTERACTING 2 (VNI2) & 0.990 & 6 & NAC_49 \\
\hline Ce_contig85206 & $\mathrm{TF}$ & AT2G27990 & BEL1-LIKE HOMEODOMAIN PROTEIN 8 (BLH8) & 0.893 & 6 & TALE_22 \\
\hline Ce_contig23430 & TF & AT4G01250 & WRKY22 & 0.957 & 6 & WRKY $\_25$ \\
\hline Ce_contig27558 & TF & AT4G23810 & WRKY 53 & 0.974 & 6 & WRKY_29 \\
\hline Ce_contig33086 & $\mathrm{TF}$ & AT3G56400 & WRKY70 & 0.963 & 6 & WRKY_34 \\
\hline Ce_contig60019 & TF & AT4G01250 & WRKY22 & 0.909 & 6 & WRKY_50 \\
\hline Ce_contig75830 & TF & AT5G13080 & WRKY75 & 0.913 & 6 & WRKY_59 \\
\hline
\end{tabular}

These included known photosynthesis regulators (bold in Table 2) such as the GRAS genes GAI/RGA (Ce_contig18469/CeGRAS_16) and RGAL3 (Ce_contig31926/CeGRAS_23) known to regulate the gibberellins signaling to repress photomorphogenesis in response to light, PHYTOCHROME B (Ce_contig13510/CePHYB) and the phytochrome A signal transduction GRAS gene PAT1 (Ce_contig5939/CeGRAS_6), RESPONSE REGULATOR 12 (Ce_contig68433/CeARR-B_7) that mediates cytokinin response to light stress, GROWTH-REGULATING FACTOR 5 (GRF5) (Ce_contig71598/CeGRF_8) and SIGMA FACTOR 6 (CeSIG6) (Ce_contig85637/CeSIG_5) involved in the chloroplast response; four homologs of ZINC FINGER PROTEIN 10 (Ce_contig18795/CeC2H2_2,; Ce_contig46000/CeC2H2_40, Ce_contig76425/CeC2H2_62, and Ce_contig81969/CeC2H2_71). Interestingly, several genes related to cell proliferation and leaf morphology, which were not previously linked to photosynthesis and light response, were strictly connected to the photosynthesis network (Table 2). These genes include homologues of the Arabidopsis LOST MERISTEMS 3 (Ce_contig82634/CeGRAS_43; Ce_contig6575/GRAS_7); TEOSINTE BRANCHED, CYCLOIDEA AND PCF 14 and 20 (Ce_contig33120/CeTCP_7; Ce_contig49086/CeTCP_12); MONOPTEROS (Ce_contig38256/CeARF12), MYB DOMAIN PROTEIN 17/LATE MERISTEM IDENTITY2 (Ce_contig1183/CeMYB_2), ATHB8 (Ce_contig83059/CeHD-ZIP_41), NAC DOMAIN CONTAINING PROTEIN 83 (NAC083)/VND-INTERACTING 2 (Ce_contig47321/CeNAC_49), ASYMMETRIC LEAVES 2-LIKE 1 (Ce_contig19510/CeLBD_6) and BEL1-LIKE HOMEODOMAIN 8 (Ce_contig85206/CeTALE_22). Overall, cluster three was enriched in positive regulators of photosynthesis, whereas cluster six was enriched in redox responsive and photooxidative stress genes.

\subsection{TF-PHOTO Genes Differentially Expressed in Broad Versus Curly Leaves}

We next examined genes that were always significantly differentially expressed between broad leaves escaroles ('Flester' and 'Confiance') and curly leaves endives ('Domari' and 'Myrna') over the two production years. Only three transcription factors were found invariably differed in their expression between endives and escaroles, which were homologous to the Arabidopsis TFs BREVIS RADIX-like 3 (Ce_contig84656/CeBRX_1), ETHYLENE-RESPONSIVE TRANSCRIPTION FACTOR RAP2-12 (Ce_contig50460/CeERF_72), and MYB113 (Ce_contig5865/CeMYB_77), which were placed in 
cluster five, eight and three, respectively. The differential expression of these genes was confirmed by qRT-PCR in mature leaves. Amongst the three genes, CeMYB_77 and CeERF_72 were reconfirmed as differentially expressed in younger leaves, whereas the expression of CeBRX_1 was not detectable in young leaves in our qPCR analysis (Figure 8).

(a)

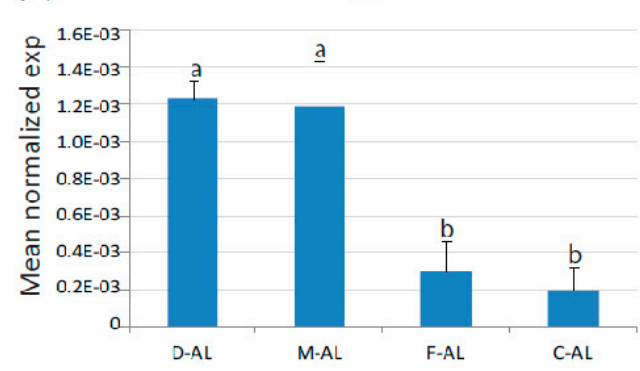

(c)

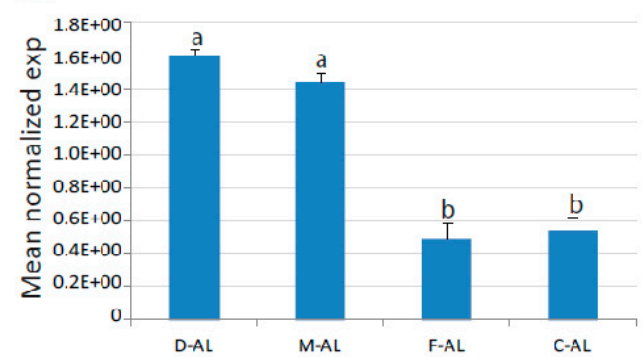

(e)

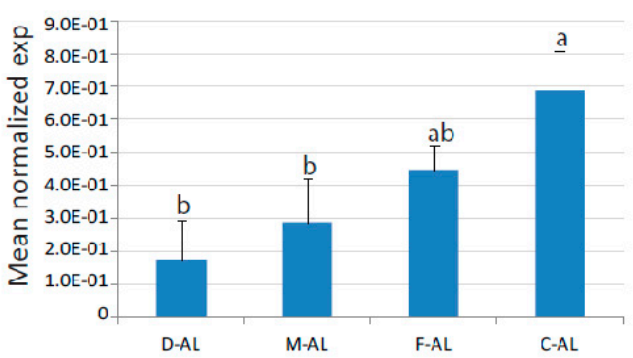

(b)

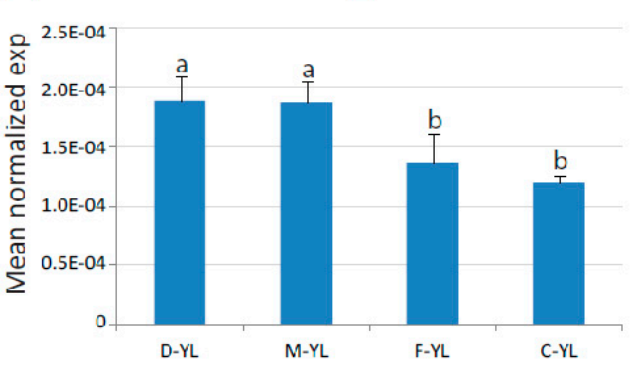

(d)

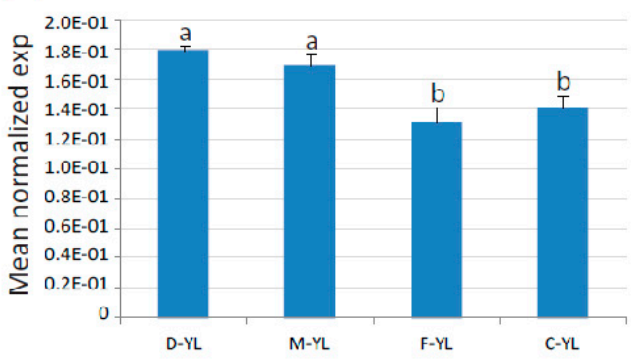

(f)

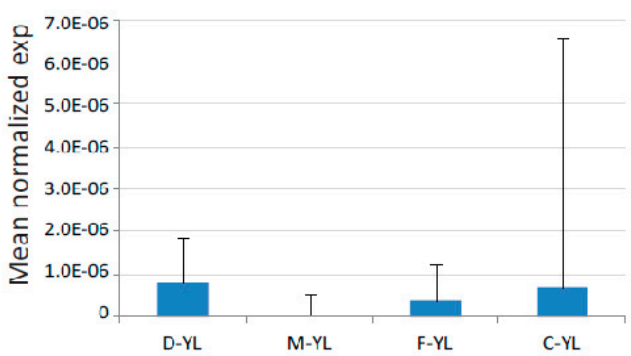

Figure 8. Expression of the three identified TF DEGs in adult (AL) and young (30-day-old, YL) leaves of endives ('Domari', D and 'Myrna', M) and escaroles ('Flester', F and 'Confiance', C) analyzed by quantitative real-time PCR. (a-b) Expression of CeMYB_77 in adult and young leaves, respectively; $(\mathbf{c}-\mathbf{d})$ expression of $C e E R F \_72$ in adult and young leaves, respectively; and (e- $\left.\mathbf{f}\right)$ expression of CeBRX_1 in adult and young leaves, respectively. Data represent the average of two biological replicates with three technical replicates each. Error bars represent SD. Letters indicate significant differences.

\section{Discussion}

The leaf shape adaptive value in relation to its photosynthetic activity represents a standing question that is both of fundamental and applied interest. We addressed this issue in C. endivia (escaroles and endives), a typical Mediterranean species of the Asteraceae (or Compositae) that has been cultivated since ancient times in the Mediterranean basin. C. endivia is a close relative of Lactuca sativa, a crop model species for the Asteraceae that represents one of the largest and most successful flowering plant family [28]. Due to the striking morphological diversity of their leaves, escaroles and endives represent a good model to study the relationship between leaf shape and photosynthetic activity. 


\subsection{The Regulatory Network of Photosynthesis in the Leaves of C. endivia}

We took advantage of an in-house produced transcriptome [25] and NGS leaf gene expression datasets to extract transcription profiles of leaf TFs and photosynthesis-related genes to explore regulatory networks in the leaves at the system level. To this purpose, transcriptome and RNA-seq data were deeply refined to obtain a reliable non-redundant gene expression database (TF-PHOTO) suitable for cluster and gene co-expression analysis. Clustering gene expression data allows to identify substructures in the data, and identify groups of genes that may share a biological function or be under the same transcriptional control (co-regulated) [31]. GCN are graphical representations of complex interactions where genes are represented by nodes, and edges connect genes that are significantly co-expressed [34]. Cluster analysis and GCN approaches successful identified the photosynthetic transcriptional regulatory network occurring in leaves and the candidate hub genes that may rule the photosynthesis transcriptional network. The identified regulatory network involved known genes of two antagonistic pathways. one concerning light signal transduction to promote the expression of photosynthesis master regulators and activate chloroplast response and downstream antenna, photosystem, and rubisco gene expressions (genes in cluster three). The other related to photooxidative stress, RS, and unfolded protein response (UPR) (genes in cluster six). This is consistent with the large increase in the production of reactive oxygen species (ROS) derived from light-driven energy transfer and electron transport during the photosynthetic process [5]. ROS are key components of chloroplast-nucleus RS pathways and also link to UPR through specific plastid signals [42]. Redox changes can influence the susceptibility of photosynthesis to high-light-induced inhibition and also modulate chloroplast-to-nucleus signaling and the transcriptional responses of leaves to high light [5]. Cluster analysis pointed to a major role of the AtPIF1/PIL5 homologue CebHLH_64 and the AtbZIP17 homologue CebZIP_41 in determining the characteristic gene expression profiles in cluster three and cluster six, respectively, based on their closeness to the respective cluster cores. This finding is in contrast with the known function of AtPIF1/PIL5 as a negative regulator of PHYB-induced light response and chloroplast biogenesis. However, as other two PIF1/PIL5 homologues are present in cluster six and eight, this member may represent an example of gene neofunctionalization, or its expression profile may not correspond to its protein activity that, in Arabidopsis, is regulated by phytochrome-induced rapid degradation [43]. The Arabidopsis bZIP17 is a membrane-associated basic-leucine zipper TFs that resides in the endoplasmic reticulum (ER). It was shown to act as a plant stress sensor/transducer that in response to stress is activated by proteolytic release of the $\mathrm{N}$-terminal from the ER membranes allowing its translocation to the nucleus [44]. It is tempting to speculate that CebZIP_41 might have a major role in transducing the ROS signal derived from the photosynthesis-induced photooxidative stress to activate the ROS-mediated transduction network [45].

Network topology is the layout of nodes and edges, and the topological properties determine the functional aspects of the relationships [34]. Parameters derived from network local properties are commonly used for node ranking to identify essential genes in the network [46]. Topological analysis of the whole TF-PHOTO GCN identified several candidate hub genes that may have a central role in regulating the leaf transcriptome as a whole. These genes belong to either cluster three or cluster six, indicating a prominent role of the photosynthetic function in the global leaf gene expression (yellow nodes in Figure 9). 
Cluster $6 \quad$ Cluster 3

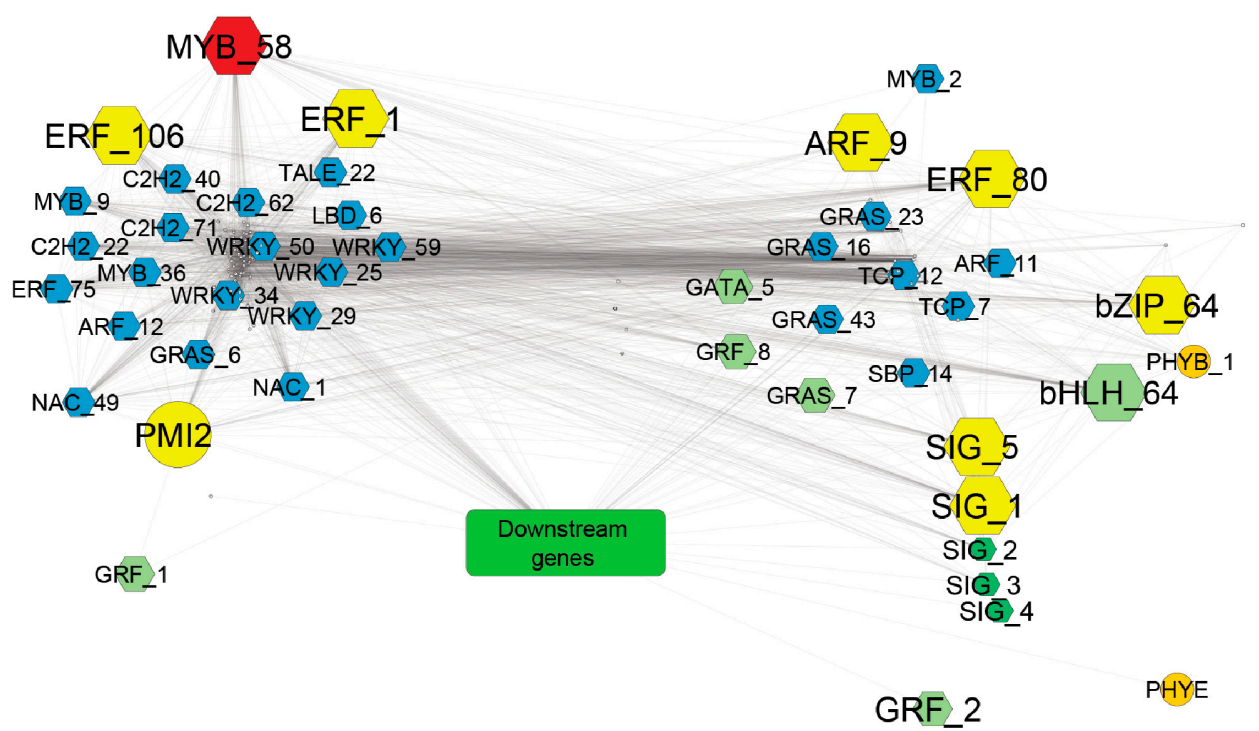

Figure 9. GCN network of photosynthesis and developmental genes from cluster three and six. Downstream genes (represented by the green box) are those involved in the photosynthetic process, which include Rubisco subunits, light harvesting complex, photosynthetic electron transfer, photosynthesis I, and photosystem II. Hexagonal shapes indicate TFs. Colors were used as follows: yellow, top-ranked hub genes; red, the gene with the highest degree in the global TF-PHOTO GCN; light green, master regulators of photosynthesis; dark green, chloroplast response genes; and light blue, developmental genes that may represent novel players in the interplay between leaf development and photosynthesis. Only significant $(p \leq 0.05)$ pairwise correlations with $r \geq|0.9|$ were considered to obtain this GCN network.

Four of them are homologous to known regulators of photosynthesis and include: AtARR12, which mediates cytokinin response to light; the sigma factor SIGA and the sigma factor SIGF, which positively regulate chloroplast response and biogenesis; and $A t A B F 2$, which is involved in the ABA-mediated chlorophyll degradation and leaf senescence [47]. However, the $A B F 2$ homologue Ce_contig73259/CebZIP_64 belonged to cluster three and was highly co-expressed with photosynthesis-induced downstream genes and was downregulated in the 'Flester' cultivar. This finding may underlie a different function of this homologue in C. endivia leaves. Regarding the other identified hubs, three ethylene responsive factors (ERFs) were amongst the top-ranked genes. ERFs act as critical downstream components of the ethylene signaling in regulating plant development and stress responses, but little is known about their role in regulation of photosynthesis [48]. Interestingly, overexpression of $H A R D Y$, an AP2/ERF gene from Arabidopsis, showed enhanced drought tolerance in rice by a reduction in transpiration and improvement of photosynthesis, probably due to an increase in leaf biomass and bundle sheath cells [49]. Differently, the rice AP2/ERF-N22 gene is able, when overexpressed, to increase carotenoid levels and reduce chlorophyll content, thus, leading to reduced photosynthetic rate and efficiency [50]. A few ERF genes were shown to promote chlorophyll degradation during senescence [51,52], whereas overexpression of the citrus CitERF13 gene in N. tabacum leaves resulted in a significant decrease in net photosynthetic rate and of Fv/Fm ratio [53]. These data indicate contrasting roles of ERFs in the photosynthetic pathway and are consistent with our data that place two ERFs, Ce_contig147/ERF_1 and Ce_contig85235/ERF_106, in cluster six, and Ce_contig59871/ERF_80 in cluster three. A homologue of the AUXIN RESPONSE FACTOR 9 Ce_contig36168/CeARF_9, is also amongst the 10 top-ranked genes in the GCN (Figure 9). $C e A R F \_9$, together with three other $A R F s$, co-expressed with many different important regulators of the photosynthetic network, such as the Arabidopsis homologues of PHYB, ABF2, ARR12, as well 
as several SIG and GAI, highlighting a prominent role of auxin response in integrating signals from different pathways into a developmental frame.

Overall, the identification of several hormone response genes as potential hubs in the TF-PHOTO regulatory network points to a major role of hormone signaling in integrating the antagonistic transcriptional responses related to the photosynthetic function of the leaf. In addition to the 10 top-ranked genes, the gene CeMYB_58, placed in cluster six, showed the highest number of connections in the GCN and can also be considered a major hub. MYB genes are involved in many aspects of plant development and in the response to environmental cues [54-56]. The analysis of the amino acid sequence of CeMYB_58 showed a high similarity with the Arabidopsis MYB TFs belonging to the subgroup 22, namely, MYB73, MYB70, MYB44, and MYB77. These MYBs seem to be involved in the activation of different pathways related to plant hormone signaling and stress response [57], but their role in photosynthesis-related processes is completely unknown. CeMYB_58 is strongly positively correlated with CebZIP_41/AtbZIP17 and CePMI2/AtPMI1, and strongly anticorrelated to genes encoding subunits of the chloroplast $\mathrm{NAD}(\mathrm{P}) \mathrm{H}$ dehydrogenase complex and a violaxanthin deepoxidase (VDE). VDE catalyses the conversion of violaxanthin to zeaxanthin through de-epoxidation [22] and is a key step of the xanthophyll cycle, which largely contributes to nonphotochemical quenching (NPQ) to avoid photoinhibition, occurring when the light energy absorbed by plant leaves exceeds its consumption, through the dissipation of excessive energy as heat [58]. Moreover, VDE is involved in ABA biosynthesis [22], then it may have a role in integrating the hormone signaling and the photosynthetic function of the leaf. A role of $C e M Y B_{-} 58$ in the negative regulation of $V D E$ is plausible.

Gene expression analysis at the leaf system level, as well as physiological and biochemical analysis, failed to identify differences in the photosynthetic regulatory networks and photosynthetic performance related to the different leaf shapes of endives and escaroles. Leaf morphology did not seem to influence photosynthetic properties in the C. endivia genotypes here analyzed, and the differences observed in the the endive and escaroles cultivars were genotype dependent. However, the robustness of our cluster and GCN analyses allowed us to investigate the relationship between photosynthesis and leaf development genes under the so-called "guilt by association" rule, which provides a powerful framework to associate functions within a gene expression module based on correlated gene expression pathways [47]. We identified genes involved in the developmental processes as strictly associated to the photosynthetic regulatory clusters. Among them, several were already described to participate in light response processes, whereas other have not been previously associated to photosynthesis-related pathways. The latter may represent novel players in the interplay between leaf development and photosynthesis and will be described in the next paragraphs.

\subsection{Developmental Genes in Cluster Three Linked to Positive Regulation of Photosynthesis}

Cluster three contains several homologues of Arabidopsis known developmental genes that participate in light response processes such as PHYB, the GRAS genes GAI and RGL3, ARR12, GRF5, SIG6, and MYB17 (Table 2) [8]. GRAS proteins play important roles in plant growth and development ranging from GA signaling, light signal transduction, and axillary shoot meristem formation [59]. In cluster three, in addition to GAI and RGL3, we found two homologues of Arabidopsis LOST MERISTEMS 3 (LOM3/SCL6-IV) (CeGRAS_43 and CeGRAS_7 in Table 2), which play vital roles in the proliferation of meristematic cells promoting shoot indeterminacy via a non-cell-autonomous pathway [60]. Moreover, three scarecrow-like (SCL) proteins, including AtSCL6-IV, were shown to be targeted by miR171 to negatively regulate chlorophyll biosynthesis [61] and may link chloroplast development and cell proliferation. CeGRAS_43 expression was highly correlated with genes encoding thylakoid membrane-associated proteins like THYLAKOID RHODANESE-LIKE (TROL) and PSB photosystem II subunits. Interestingly, CeGRAS_43 expression was also highly correlated to CeGRF5, which plays a major role in stimulating chloroplast division and positively affects leaf size when overexpressed [62]. CeARF_11, a homologue of Arabidopsis ARF16, was also co-expressed with several photosynthetic downstream genes and with one of the top-ranked genes in the GCN, CeARF_9. Auxin 
response regulators have been recently shown to play antagonistic roles in photosynthesis regulation in tomato, and the SIARF6A gene was shown to positively affects photosynthesis in fruits and leaves of tomato plants [63]. Our data are consistent with a major role of auxin response in coordinating photosynthesis and leaf development.

Three MADS box homologous to the Arabidopsis SVP, MAF3, and AGL62 were also in cluster three. SVP is a well known regulator of flowering transition in response to light and ambient temperature, however, was also proposed to affect steady-state photosynthetic rates [64]. Amongst these genes, the C. endivia homologue of MAF3 (CeMIKC-MADS_13) was highly connected in the GCN and was strongly co-expressed with several photosynthetic genes and the GCN hub CeERF_80.

Two homologues of the Arabidopsis TEOSINTE BRANCHED, CYCLOIDEA AND PCF 14 and 20 (CeTCP_7; CeTCP_12) were found in cluster three. Members of the Arabidopsis TCP family act on several aspects of plant development [65]. CeTCP_7, homologous of TCP14, was highly connected in the GCN and with the GCN hub CeERF_80 and is part of the same regulatory subnetwork. AtTCP20 is involved in the control of multiple antagonistic processes during leaf growth by linking regulation of growth and cell division via the jasmonic acid (JA) pathway [66]. In developing leaves, TCP20 can also directly control the expression of genes involved in iron homeostasis [67] which is crucial for proper photosynthetic electron transport chain functioning and chloroplast development. However, tcp20 knocked-out analyses did not reveal direct effects on photosynthetic efficiency [68], and suggested a role as a negative regulator of leaf aging [69]. The endive homologue of TCP20,CeTCP_12, had a few strong links in the GCN but was highly correlated with a homologue of the Arabidopsis ABF2,CebZIP_64. However, CebZIP_64 involvement in photosynthesis in C. endivia seems opposite to that observed for $A B F 2$ that mediates ABA-dependent chlorophyll degradation and aging in Arabidopsis [47].

The Arabidopsis ATHB8 is a known regulator of vascular development [70]. The ATHB8-like gene of endive (CeHD-ZIP_41) shares maximal sequence identity with the HOX32 gene of rice, which was suggested to play a key role in the interplay between leaf development and proper photosynthetic machinery functioning [71].

\subsection{Developmental Genes in Cluster Six Antagonistic to Photosynthesis}

Cluster six was enriched in genes related to the photooxidative stress and ROS production that derived from light-driven energy transfer and electron transport during the photosynthetic process [5]. Chloroplast redox homeostasis and ROS are key components of chloroplast-nucleus retrograde signaling pathways [72] and also link to UPR through specific plastid signals [73]. RS is a complex intracellular signaling pathway that chloroplast utilizes to convey information on their physiological states to the nucleus and modulate the expression of nuclear genes accordingly, coupling physiological state with developmental signaling [74,75]. Recently, Martin et al. [18] showed that the phytochrome and RS pathways converge antagonistically to regulate the expression of GLK1, a key regulator of a light-induced transcriptional network central to photomorphogenesis.

Cluster six harbors several genes involved in different developmental processes. Among these, we found an homologue of the Arabidopsis REDOX RESPONSIVE TRANSCRIPTION FACTOR 1 (RRTF1) (CeERF_75), a central TF in fast retrograde signaling to high light response [76,77]. CeERF_75 was highly connected in the GCN, with very high correlation with several TFs (including other ERF members) confirming the central role of RRTF1-like proteins in the redox responsive regulatory co-expression network acting during RS [77].

Cluster six also contained four homologues of the Arabidopsis SALT TOLERANCE ZING FINGER (ZAT10) (Table 2), which is involved in development and growth in response to oxidative stress. Constitutive expression of ZAT10 elevates the expression of reactive oxygen defence transcripts and results in palisade tissue formation $[78,79]$. The four endive homologues were highly co-expressed and tightly connected to the GCN. Specifically, CeH2C2_71 established 412 connections and can be considered a main hub in the oxidative stress response. Intriguingly, CeH2C2_71 and CeERF_75 were strongly co-expressed, suggesting a crosstalk between ZAT10 and the RRTF1-mediated RS pathway. 
CeNAC_1 and CeNAC_29, homologous to the Arabidopsis NAC053 and VNI2, were also part of the same major $C e H 2 C 2 \_71$ and $C e E R F \_75$ network and may link oxidative response to activation of transcription factors involved in leaf senescence. NAC053 is thought to promote ROS production by binding directly to the promoters of genes encoding ROS biosynthetic enzymes during drought-induced leaf senescence in a network involving WRKY genes [80], whereas VNI2 is involved in vascular development and plays a role in the age-dependent induction of stress resistance [81]. Several WRKY homologous to Arabidopsis WRKY22, 53, 75 were found in cluster six. WRKY22, WRKY53 and WRKY75 are involved in leaf senescence. WRKY22 participates in the dark-induced senescence signal transduction pathway [82], and its transcription is suppressed by light and promoted by darkness and by $\mathrm{H}_{2} \mathrm{O}_{2}$. WRKY53 play a central role in senescence regulation $[83,84]$ and in the crosstalk between early and late stages of leaf development [85]. Three endive homologues, CeWRKY_25, 29, and 34, were strongly co-expressed and highly connected in the GCN, and co-expressed with HEAT SHOCK FACTOR TFs and CebZIP_41/AtbZIP17, a major player in the unfolded protein response in the ER that we also identified as a main transcriptional driver in cluster six.

Furthermore, $M Y B$ genes were also found in cluster six, in particular the homologues of Arabidopsis MYB14 (CeMYB_9) and MYB102 (CeMYB_36). MYB102 is involved in the integration of wounding and osmotic stress signals [86] and it is a possible interactor of the SWI/SNF chromatin remodelling ATPase BRAHMA, which promotes leaf growth by stage-specific modification of CK responses [87].

A TALE homeobox homologous to the Arabidopsis BLH8 (CeTALE_22) was placed in cluster six. TALEs are encoded by two small subfamilies in the Arabidopsis, KNOX and BLH [88]. TALEs are master controllers of plant development that regulate the fine equilibrium between cell fate maintenance and differentiation in the lateral organ formation at the shoot apical meristem (SAM) and during leaf morphogenesis and leaf marginal outgrowth [88,89]. In Arabidopsis, BLH8 interact with the class 1 KNOX SHOOT MERISTEMLESS and BLH9 to restrict organogenesis at the SAM [90]. In endive leaves, the expression of CeTALE_22 was highly correlated with the expression of CeLBD_6, the endive homologue of ASL1, which, in Arabidopsis, seems to be involved in the transcriptional regulation of class 1 KNOX during lateral organ differentiation [91]. Interestingly, members of class I KNOX were found to act as transcriptional activators of SIGLK2 in tomato to promote chloroplast [92], whereas a BLH, SIBEL11, was shown to play an important role in chlorophyll synthesis and chloroplast development in tomato fruits [93].

\subsection{Transcription Factors that Are Differentially Expressed Between Broad-and Curly-Leaved C. endivia Cultivars}

Finally, three genes that are differentially expressed between broad and curly leaves were identified and will be further investigated to assess their role in leaf development and shape.

Among them, CeMYB_77 belonged to the photosynthesis regulatory cluster thee. The amino acid sequence of CeMYB_77 is highly similar to those of the Arabidopsis genes AtMYB113/PAP3 and AtMYB75/PAP1, involved in anthocyanin biosynthesis and accumulation [13,94]. Interestingly, AtMYB75/PAP1 is involved in a light-dependent signaling pathway. JA promotes anthocyanin accumulation under far-red light through a signaling pathway consisting of PHYA, COP1, and MYB75/PAP1 [95]. Moreover, MYB75/PAP1 physically interacts with the KNOX transcription factor KNAT7, to form functional complexes that contribute to the regulation of secondary cell wall deposition and that integrate the metabolic flux through the lignin, flavonoid, and polysaccharide pathways in Arabidopsis [96]. Thus, a role of CeMYB_77 in light-mediated anthocyanin production in C. endivia can be hypothesized.

The other two DEGs, CeERF_72 and CeBRX_1, homologous to AtRAP2-12 and AtBRX3, were found in cluster eight and five, respectively. AtRAP2.12 exerts a major control in the metabolic reprogramming of cells under hypoxic conditions [97,98], but a specific function in leaf development or shape has not been described. In Arabidopsis, BRX proteins form a small family that was shown to control the extent of cell proliferation and elongation in the growth zone of the root tip [99]. BRX 
proteins are highly similar, contain four highly conserved domains of unknown function, and a specific role in leaves has been so far described.

The main regulatory pathways involved in leaf shape determination and leaf margin serrations in Arabidopsis and C. irsuta, CUP-SHAPED COTYLEDON2 (CUC2) boundary genes, SHOOT MERISTEMLESS (STM), and REDUCED COMPLEXITY (RCO) [100,101] were not expressed in mature leaves and their role in determining leaf shape in $C$. endivia could not be addressed at this stage.

\section{Materials and Methods}

\subsection{Biological Material and Morphological Analysis}

Cichorium endivia L. curled-leaved endives 'Domari' and 'Myrna' (C. endivia var. crispum), and broad-leaved escaroles 'Confiance' and 'Flester' (C. endivia var. latifolium) seeds were provided by the Enza Zaden company (www.enzazaden.com). Plants used for transcriptomic analysis were first grown in a nursery, then three-week-old seedlings were moved into an open field $\left(8.2 \mathrm{plants} / \mathrm{m}^{2}\right)$ and harvest occurred during the second half of November (86 days after sowing) as described in Testone et al. [25]. Two production cycles were carried out in 2011 and 2012, in the same location and in the same time of the year.

Seeds were sown in water wet paper in Petri dishes and germinated in the light in a growth chamber at $23{ }^{\circ} \mathrm{C}$ under long-day conditions $(16 \mathrm{~h} / 8 \mathrm{~h}$ light/dark at $150 \mu \mathrm{mol})$. After one week from germination, plantlets were transferred in soil pots, watered every two days and nutritive solution added once a week. For photosynthesis measurements, 21-day-old plantlets were placed in bigger pots in the soil and transferred to a greenhouse. The experiment was set up in a completely randomized design with at least three replicates (pots) for each of the four cultivars. Pots were placed during summertime (July to August) in a greenhouse under natural photoperiod (about $14 \mathrm{~h}$ ), with mean (night and day) temperatures of 22.1 to $28.8{ }^{\circ} \mathrm{C}$ and relative humidity of $50 \%$ to $60 \%$. Plants were irrigated daily by supplying the water loss for evapotranspiration to maintain $50 \%$ of the water holding capacity, evaluated before starting the experiment.

For morphological analysis, leaf length, leaf width, and number of serrations were recorded in 10 plants per each cultivar from 10 to 21 days after germination. For calculating the leaf area exposed to incident light, pictures were taken, and areas were calculated using the imaging software NIS-Elements-BR Ver. 2.1 (Nikon).

\subsection{RNA Isolation, Sequencing, and Expression Analysis}

For the RNA-seq analysis of the C. endivia production cycle 2011, leaf sampling (three biological replicates per cultivar), total RNA extraction and quality assessment, cDNA libraries synthesis, and Illumina sequencing were as described in Testone et al. [25]. Raw sequenced reads were checked and filtered as previously described [25], and aligned to the reference transcriptome using Kallisto [102]. Digital gene transcription levels were expressed in RPKM (reads per kilobase per million mapped reads) values.

For real-time RT-PCR (qRT-PCR) gene expression analysis, total RNA was isolated (TRIzol, Invitrogen), purified (Plant RNeasy RNA Cleanup, Qiagen, Hilden, Germany ), and treated with DNase I (Qiagen). First-strand cDNA was synthesized from $1.5 \mu \mathrm{g}$ of total RNA using the Superscript III first-strand synthesis system (Invitrogen). Primer design was performed using Primer3 software [103], followed by primer test specificity with the Primer-Blast NCBI tool in the Cichorioideae database. Quantitative RT-PCR reactions were performed using the Eco Real-Time PCR System (Illumina), following manufacturer's instructions using 50 to $70 \mathrm{ng}$ of template cDNA (Biotool easy mix with Eva green fluorophor) and $300 \mathrm{nM}$ final primer concentration. Cycling conditions were as follows: $95^{\circ} \mathrm{C}$ for $10 \mathrm{~min}, 50$ cycles at $95^{\circ} \mathrm{C}$ for $5 \mathrm{~s}, 68^{\circ} \mathrm{C}$ for $15 \mathrm{~s}$, and $72{ }^{\circ} \mathrm{C}$ for $15 \mathrm{~s}$. The experiments included at least two biological and three instrumental replicates. Gene expressions were normalized against the ACTIN reference gene [104] and mean normalized expressions were calculated using the Q-Gene 
program [105]. The primers used are listed in Table S6. For confirmation of RNA-seq data, the purified total RNA used for the transcriptomic analysis was used. For gene expression analysis in young leaves, total RNA was extracted from pools of leaves (three young fully expanded leaves from three different 30-day-old plants) of the four C. endivia cultivars (two biological replicates).

\subsection{TF-PHOTO Database Construction}

The transcriptome of C. endivia (cv 'Domari'; NCBI TSA accession: GGQM00000000.1) obtained in our lab [25] was used to construct the TF-PHOTO database. The transcription factors previously identified based on the PlantTFDB database (Jin et al. NAR 2014) were used for further refinements. Contigs homologous to the L. sativa TFs annotated in PlantTFDB or published [27] were searched in the $C$. endivia transcriptome and added to the initial TF database if not present. To obtain reliable non-redundant full-length and near full-length TF transcripts (transcript completeness $\geq 0.7$ ), sequences were aligned to the L. sativa genome [28] (1 hint/locus) and full-length percentage prediction FL\% $\geq 0.7$, calculated as the length of $C$. endivia deduced protein/L. sativa annotated protein. Predictions were further validate with the MapMan package [29] by binning of Arabidospis IDs of the corresponding TFs to MapMan bins by the Mercator application [106]. Finally, only transcript expressed in leaves (genes with read count $<10$ in more than $90 \%$ of the samples, following WGCNA platform suggestions [107] in RNA-seq leaf data (NCBI Bioproject PRJNA417356) were considered. This pipeline allowed to reduce the initial 5476 predicted TFs to 1560 bona fide leaf TFs.

As for photosynthesis and photosynthesis-related genes (energy dissipation and reactive oxygen species detoxification), the selection criteria included: (i) homology with Arabidopsis genes belonging to GO:0015979 (photosynthesis), GO:0009813 (flavonoid metabolic processes), GO:0016116 (carotenoid metabolic process), and GO:0019852 (ascorbic acid metabolic process) terms; (ii) transcript completeness $\geq 0.7$; and (iii) leaf expression occurrence. All the selected transcripts were aligned to the latest release (GenBank accession GCF_002870075.1) of the L. sativa reference genome [28] by GMAP [108] (Table S2).

\subsection{K-Means Cluster Analysis and Gene Co-Expression Network Construction}

For the K-means cluster analysis, we used RPKM means of the TF-PHOTO genes of endives and escaroles from leaf RNA-seq of plants grown in two independent production cycles (from 2011 to 2012). The data were $\log$-transformed using $\log 2(x+1)$ for normalization and scaled. To determine the optimum number of clusters, the sum of squared error (SSE), the average silhouette width, and the Calinski-Harabasz index, based on the intra- and intercluster sum of squares, methods were used. The pipeline of the analysis is shown in Figures S1-S4. Eventually, we empirically established the optimum number at 8 using a posteriori validation that consists in correlating cluster centroids to each other and then choose the highest number of clusters with centroids maximum correlation below 0.8. Data scaling, K-means clustering, and visualization were performed in $\mathrm{R}$.

For GCN construction and analysis, we used RPKM from biological replicates in the four cultivars for two production cycles (23 RNA-seq samples in total). The data were log-transformed using $\log 2(\mathrm{x}$ +1 ) for normalization and Pearson pairwise correlation analysis was conducted across the selected samples using the "corrplot" and "hclust" packages of R software [109]. Significant correlations ( $p$ value $\leq 0.05)$ with a Pearson's correlation coefficients $(r) \geq|0.8|$ were used for the construction of co-expression networks and network analysis in the Cytoscape software platform v. 3.5.1 [33].

\subsection{Chlorophyll Fluorescence Measurements}

After 15 days of growth under greenhouse conditions, chlorophyll fluorescence measurements were performed to assess the efficiency of the photosynthetic apparatus of $C$. endivia cultivars. In particular, the maximal quantum efficiency of PSII photochemistry $\left(\mathrm{F}_{\mathrm{v}} / \mathrm{F}_{\mathrm{m}}\right)$ and the quantum efficiency of PSII photochemistry (ФPSII) were measured on two fully developed leaves per plant using a chlorophyll fluorescence imaging (MAXI-Imaging-PAM, Walz, Germany). Leaves were dark adapted for at least 30 min before determining $\mathrm{F}_{0}$ and $\mathrm{F}_{\mathrm{m}}$ (minimum and maximum fluorescence, respectively). 
The $\mathrm{F}_{\mathrm{v}} / \mathrm{F}_{\mathrm{m}}$ value was calculated as $\left(\mathrm{F}_{\mathrm{m}}-\mathrm{F}_{0}\right) / \mathrm{F}_{\mathrm{m}}$. Leaves were then adapted to a photosynthetic photon flux density (PPFD) of $370 \mu \mathrm{mol} \mathrm{m}{ }^{-2} \mathrm{~s}^{-1}$ (near to the growth light intensity used in the experiment) and a saturating pulse was applied to determine the maximum fluorescence $\left(\mathrm{F}_{\mathrm{m}}{ }^{\prime}\right)$ and steady-state fluorescence $\left(\mathrm{F}_{\mathrm{s}}\right)$ during the actinic illumination. Saturation pulse images and values of the chlorophyll fluorescence parameters were captured. The $\Phi P S I I$ value was calculated using the formula $\left(\mathrm{F}_{\mathrm{m}}{ }^{\prime}-\right.$ $\left.\mathrm{F}_{\mathrm{s}}\right) / \mathrm{F}_{\mathrm{m}}{ }^{\prime}$. The apparent photosynthetic electron transport rate (ETR) was calculated as follows: ETR = $\Phi P S I I \times$ PPFD $\times 0.5 \times$ Abs, where Abs is the apparent absorptivity of the leaf surface and 0.5 is the fraction of light absorbed by PSII antennae [110]. The Abs value was automatically calculated, pixel by pixel, from the R (red) and NI (near infrared) images using the formula, Abs $=1-(\mathrm{R} / \mathrm{NI})$. Moreover, the Imaging-PAM software was used to select, on the chlorophyll fluorescence images, four area of interested (AOI), two in the central part of the leaf (internal) and two in the outer zones (external), in order to evaluate the spatial heterogeneity of the photosynthetic activity on the leaf surface.

\subsection{Determination of Chlorophyll and Total Carotenoids Content}

Measurements of total chlorophyll content were performed using the chlorophyll meter readings (SPAD-502, Minolta Camera Co., Osaka, Japan) on at least two fully developed leaves per plant. Four SPAD readings were taken from the widest portion of the leaf lamina, while avoiding major veins. The four SPAD readings were averaged to represent the SPAD value of each leaf. SPAD values were converted to chlorophyll content $\left(\mu \mathrm{g} \mathrm{cm}^{-2}\right)$ using the following equation [111]:

$$
\text { chlorophyll content }=(99 \times \operatorname{SPAD} \text { value }) /(144-\mathrm{SPAD} \text { value })
$$

For biochemical analysis, chlorophyll-a, chlorophyll-b, and carotenoid pigments of plants ( $0.2 \mathrm{~g})$ were extracted in $10 \mathrm{~mL} \mathrm{80 \%} \mathrm{chilled} \mathrm{acetone} \mathrm{in} \mathrm{the} \mathrm{dark.} \mathrm{After} \mathrm{centrifugation} \mathrm{at} \mathrm{10,000 \times g} \mathrm{for} 10 \mathrm{~min}$ at $4{ }^{\circ} \mathrm{C}$, the absorbance of the supernatants was read spectrophotometrically at 663,647 , and $470 \mathrm{~nm}$. $\mathrm{Chl}-\mathrm{a}, \mathrm{Chl}-\mathrm{b}$, and carotenoid contents were determined according to the equations described by [112] and the results expressed in mg carotenoids per gram of FW.

\subsection{Measurements of Spectral Reflectance and Spectral Reflectance Indices}

Absolute reflectance spectra of the plants were collected using an analytical spectral device (ASD) Inc. Field Spec $(3$ as reported by [113]. The spectral range of the instrument is 350 to $1025 \mathrm{~nm}$ with a $1.4 \mathrm{~nm}$ bandwidth. A white reference Spectralon panel was used to calibrate spectral measurement. An external $50 \mathrm{~W}$ halogen lamp was set up with an illumination angle of $45^{\circ}$. Besides the lamp, there were no other sources of illumination in the laboratory, and therefore no environmental contribution. The instrument fiber optic was fit through a mounting gun attached to a tripod and adjusted to a nadir viewing position. The distance from the fiber optic to the sample was $20 \mathrm{~cm}$, which translated to a field of view (FOV) of approximately $90 \mathrm{~mm}$ (using a $25^{\circ}$ bare fiber optic). Reflectance spectra were recorded as the ratio of sample data to white reference ( $99 \%$ reflectance Spectralon panel) data under the same illumination and viewing conditions. The mean of the five spectra was then determined to provide a single spectral value. Several spectral reflectance indices were derived from the collected data and are reported in Table S7.

\subsection{Measurement of Lipid Peroxidation Levels}

Determination of lipid peroxidation was performed by measuring malondialdehyde (MDA) content following the modified method by [114]. Frozen samples were homogenized in a prechilled mortar and pestle with two volumes of ice-cold $0.1 \%(w / v)$ trichloroacetic acid (TCA) and centrifuged for $15 \mathrm{~min}$ at $16,000 \times \mathrm{g}$. Assay mixture containing $1 \mathrm{~mL}$ aliquot of supernatant and $2 \mathrm{~mL}$ of $0.5 \%(w / v)$ thiobarbituric acid in $20 \%(w / v)$ TCA was heated to $95^{\circ} \mathrm{C}$ for $30 \mathrm{~min}$ and then rapidly cooled in an ice bath. After centrifugation $\left(16,000 \times \mathrm{g}\right.$ for $10 \mathrm{~min}$ at $\left.4{ }^{\circ} \mathrm{C}\right)$, the supernatant absorbance $(532 \mathrm{~nm})$ was read, and values corresponding to nonspecific absorption $(600 \mathrm{~nm})$ were subtracted. The MDA 
concentration was calculated using the extinction coefficient $\left(155 \mathrm{mM}^{-1} \mathrm{~cm}^{-1}\right)$. The lipid peroxidation levels were expressed as nanomoles of MDA per gram of FW.

\subsection{Statistical Analysis}

For differential expression analysis, the read counts matrices were normalized by TMM method [115] and processed by the edgeR package [116]. Differentially expressed genes (DEGs) were analyzed for each cultivar comparison and those with false discovery rate (FDR) $\leq 0.05$ and an absolute log2 fold change $\geq 1$ were considered as DEGs.

One-way analysis of variance (ANOVA) was performed for physiological measurements, morphological and biochemical studies, and for qRT-PCR analysis. Data reported in the tables and figures refer to the average values of replicates \pm standard error (SE). Normally distributed data were evaluated by employing Student-Newman-Keuls test at a significance level of $p \leq 0.05$ using the SPSS (Chicago, IL, USA) software tool for physiological dataset while Tukey's test with a significance of $p<0.05$, using R statistical package vers. 3.5.0 (R Core Team, 2018) for morphological biochemical and gene expression measurements.

\section{Conclusions}

Gene expression analysis at the leaf system level, a molecular, physiological, and biochemical analysis, allowed us to investigate possible links between photosynthesis and leaf morphology in $C$. endivia cultivars characterized by broad or curly leaves morphology. Although no correlation between leaf shape and photosynthetic performance was observed, important genotype-specific differences were identified and correlated to changes in gene expression of photosynthetic genes and their regulators. The first $C$. endivia database for leaf transcription factors and photosynthesis-related genes was produced and could constitute an important resource for crop breeding and genetic improvement in Asteraceae species. Robust clustering and GCN analyses allowed us to reconstruct the regulatory pathway of photosynthesis in this important crop species. A "guilt by association" approach let us identify developmental genes strictly associated to the photosynthetic regulatory network that may thus represent novel players in the interplay between leaf development and photosynthesis. Finally, the identification of three transcription factors that are differentially expressed in C. endivia broad vs. curly leaves could allow us to further investigate the genetic basis of leaf morphological diversity in Asteraceae species.

Supplementary Materials: The following are available online at http://www.mdpi.com/2223-7747/8/12/531/s1, Figures S1-S4: Methods used to determine the optimum number of clusters for K-means analyses; Figure S5: Malondialdehyde and carotenoids content in escarole and endive plants; Table S1: TF-PHOTO gene expression database; Table S2: Alignment data of TF-PHOTO genes with the genome of L. sativa; Table S3: Correlation matrix used for the GCN construction; Table S4: GCN network statistics used to obtained the top-ranked hub genes; Table S5: Chlorophyll fluorescence parameters measured in the internal and external part of escarole and endive leaves; Table S6: List of primers used for gene expression analysis by qRT-PCR; and Table S7: Spectral reflectance indices.

Author Contributions: Conceptualization, G.F., G.T., M.A.I., and E.B.; NGS, RNA-seq, DEG analysis, sequence alignment, annotations, G.T.; TF-PHOTO database construction, G.T. and G.F.; plant RNA extraction and oligo design, E.D.G., E.B., and G.F.; validation gene expression data by qRT-PCR, G.F.; cluster and GCN analyses, G.F.; initial C. endivia material mature leaves sampling and transcriptome assembly, G.T., G.M., E.D.G., M.A.I., G.F., C.N., and D.G.; plant growth and morphological analysis, C.N. and M.A.I.; biochemical analysis, M.A.I. and E.B.; photosynthetic parameters and imaging analysis, F.P.; writing—original draft preparation, G.F.; writing—review and editing, G.F., G.T., M.A.I., and E.B.

Funding: This research received no external funding.

Acknowledgments: We thank: the Enza Zaden company for providing C. endivia seed lots; the project “Innovazione e Sviluppo del Mezzogiorno - Conoscenze Integrate per Sostenibilità ed Innovazione del Made in Italy Agroalimentare, Legge no. 191/2009I of the Italian Ministry of Economy and Finance to the National Research Council" that funded the initial work on C. endivia to produce the transcriptome used in this work; and Renato Alberto Rodrigues-Pousada for critical reading of the manuscript; the undergraduate students Chiara D'Attilia and Ludovica Fumelli for help with calculation of the leaf area exposed to incident light using the Nikon imaging software. 
Conflicts of Interest: The authors declare no conflict of interest.

\section{References}

1. Ren, T.; Weraduwage, S.M.; Sharkey, T.D. Prospects for enhancing leaf photosynthetic capacity by manipulating mesophyll cell morphology. J. Exp. Bot. 2019, 70, 1153-1165. [CrossRef]

2. Fritz, M.A.; Rosa, S.; Sicard, A. Mechanisms underlying the environmentally induced plasticity of leaf morphology. Front. Genet. 2018, 9, 478. [CrossRef] [PubMed]

3. Tsukaya, H. A consideration of leaf shape evolution in the context of the primary function of the leaf as a photosynthetic organ. In The Leaf: A Platform for Performing Photosynthesis; Adams, W.W., III, Terashima, I., Eds.; Springer International Publishing: Cham, Switzerland, 2018; pp. 1-26.

4. Eberhard, S.; Finazzi, G.; Wollman, F.A. The dynamics of photosynthesis. Annu. Rev. Genet. 2008, 42, 463-515. [CrossRef] [PubMed]

5. Foyer, C.H. Reactive oxygen species, oxidative signaling and the regulation of photosynthesis. Env. Exp. Bot. 2018, 154, 134-142. [CrossRef] [PubMed]

6. Friso, G.; Giacomelli, L.; Ytterberg, A.J.; Peltier, J.B.; Rudella, A.; Sun, Q.; Wijk, K.J. In-Depth analysis of the thylakoid membrane proteome of Arabidopsis thaliana chloroplasts: New proteins, new functions, and a plastid proteome database. Plant Cell 2004, 16, 478-499. [CrossRef]

7. Martin, W.; Rujan, T.; Richly, E.; Hansen, A.; Cornelsen, S.; Lins, T.; Leister, D.; Stoebe, B.; Hasegawa, M.; Penny, D. Evolutionary analysis of Arabidopsis, cyanobacterial, and chloroplast genomes reveals plastid phylogeny and thousands of cyanobacterial genes in the nucleus. Proc. Natl. Acad. Sci. USA 2002, 99, 12246-12251. [CrossRef]

8. Wang, P.; Hendron, R.W.; Kelly, S. Transcriptional control of photosynthetic capacity: Conservation and divergence from Arabidopsis to rice. New Phytol. 2017, 216, 32-45. [CrossRef]

9. Smith, H. Phytochromes and light signal perception by plants-an emerging synthesis. Nature 2000, 407, 585-591. [CrossRef]

10. Schepens, I.; Duek, P.; Fankhauser, C. Phytochrome-mediated light signalling in Arabidopsis. Curr. Opin. Plant Biol. 2004, 7, 564-569. [CrossRef]

11. Rockwell, N.C.; Su, Y.S.; Lagarias, J.C. Phytochrome structure and signaling mechanisms. Annu. Rev. Plant Biol. 2006, 57, 837-858. [CrossRef]

12. Quail, P.H. Phytochrome photosensory signalling networks. Nat. Rev. Mol. Cell Biol. 2002, 3, 85-93. [CrossRef] [PubMed]

13. Franklin, K.A.; Quail, P.H. Phytochrome functions in Arabidopsis development. J. Exp. Bot. 2010, 61, 11-24. [CrossRef] [PubMed]

14. Yang, E.J.; Yoo, C.Y.; Liu, J.; Wang, H.; Cao, J.; Li, F.W.; Pryer, K.M.; Sun, T.P.; Weigel, D.; Zhou, P.; et al. NCP activates chloroplast transcription by controlling phytochrome-dependent dual nuclear and plastidial switches. Nat. Commun. 2019, 10, 2630. [CrossRef] [PubMed]

15. Lau, O.S.; Deng, X.W. Plant hormone signaling lightens up: Integrators of light and hormones. Curr. Opin. Plant Biol. 2010, 13, 571-577. [CrossRef] [PubMed]

16. Toledo-Ortiz, G.; Huq, E.; Rodriguez-Concepcion, M. Direct regulation of phytoene synthase gene expression and carotenoid biosynthesis by phytochrome-interacting factors. Proc. Natl. Acad. Sci. USA 2010, 107, 11626-11631. [CrossRef]

17. Leivar, P.; Quail, P.H. PIFs: Pivotal components in a cellular signaling hub. Trends Plant Sci. 2011, 16, 19-28. [CrossRef]

18. Martin, G.; Leivar, P.; Ludevid, D.; Tepperman, J.M.; Quail, P.H.; Monte, E. Phytochrome and retrograde signalling pathways converge to antagonistically regulate a light-induced transcriptional network. Nat. Commun. 2016, 7, 11431. [CrossRef]

19. Wang, L.; Gu, X.; Xu, D.; Wang, W.; Wang, H.; Zeng, M.; Chang, Z.; Huang, H.; Cui, X. miR396-targeted AtGRF transcription factors are required for coordination of cell division and differentiation during leaf development in Arabidopsis. J. Exp. Bot. 2011, 62, 761-773. [CrossRef]

20. Gollan, P.J.; Tikkanen, M.; Aro, E.M. Photosynthetic light reactions: Integral to chloroplast retrograde signalling. Curr. Opin. Plant Biol. 2015, 27, 180-191. [CrossRef] 
21. Chi, W.; Feng, P.; Ma, J.; Zhang, L. Metabolites and chloroplast retrograde signaling. Curr. Opin. Plant Biol. 2015, 25, 32-38. [CrossRef]

22. Agrawal, G.K.; Yamazaki, M.; Kobayashi, M.; Hirochika, R.; Miyao, A.; Hirochika, H. Screening of the rice viviparous mutants generated by endogenous retrotransposon Tos17 insertion. Tagging of a zeaxanthin epoxidase gene and a novel ostatc gene. Plant Physiol. 2001, 125, 1248-1257. [CrossRef] [PubMed]

23. Nicotra, A.B.; Cosgrove, M.J.; Cowling, A.; Schlichting, C.D.; Jones, C.S. Leaf shape linked to photosynthetic rates and temperature optima in South African Pelargonium species. Oecologia 2008, 154, 625-635. [CrossRef] [PubMed]

24. Strauss, S.; Lempe, J.; Prusinkiewicz, P.; Tsiantis, M.; Smith, R.S. Phyllotaxis: Is the golden angle optimal for light capture? New Phytol. 2019. [CrossRef] [PubMed]

25. Testone, G.; Mele, G.; di Giacomo, E.; Tenore, G.C.; Gonnella, M.; Nicolodi, C.; Frugis, G.; Iannelli, M.A.; Arnesi, G.; Schiappa, A.; et al. Transcriptome driven characterization of curly- and smooth-leafed endives reveals molecular differences in the sesquiterpenoid pathway. Hortic. Res. 2019, 6, 1. [CrossRef]

26. Jin, J.; Zhang, H.; Kong, L.; Gao, G.; Luo, J. PlantTFDB 3.0: A portal for the functional and evolutionary study of plant transcription factors. Nucleic Acids Res. 2014, 42, D1182-D1187. [CrossRef]

27. Meisrimler, C.N.; Pelgrom, A.J.E.; Oud, B.; Out, S.; Van den Ackerveken, G. Multiple downy mildew effectors target the stress-related NAC transcription factor LsNAC069 in lettuce. Plant J. 2019, 99, 1098-1115. [CrossRef]

28. Reyes-Chin-Wo, S.; Wang, Z.; Yang, X.; Kozik, A.; Arikit, S.; Song, C.; Xia, L.; Froenicke, L.; Lavelle, D.O.; Truco, M.J.; et al. Genome assembly with in vitro proximity ligation data and whole-genome triplication in lettuce. Nat. Commun. 2017, 8, 14953. [CrossRef]

29. Thimm, O.; Blasing, O.; Gibon, Y.; Nagel, A.; Meyer, S.; Kruger, P.; Selbig, J.; Muller, L.A.; Rhee, S.Y.; Stitt, M. MAPMAN: a user-driven tool to display genomics data sets onto diagrams of metabolic pathways and other biological processes. Plant J. 2004, 37, 914-939. [CrossRef]

30. Bryan, J. Problems in gene clustering based on gene expression data. J. Multivar. Anal. 2004, 90, 44-66. [CrossRef]

31. Altman, N.S.; Krzywinski, M. Points of significance: Clustering. Nat. Methods 2017, 14, 545-546. [CrossRef]

32. Huq, E.; Al-Sady, B.; Hudson, M.; Kim, C.; Apel, K.; Quail, P.H. Phytochrome-interacting factor 1 is a critical bHLH regulator of chlorophyll biosynthesis. Science 2004, 305, 1937-1941. [CrossRef] [PubMed]

33. Shannon, P.; Markiel, A.; Ozier, O.; Baliga, N.S.; Wang, J.T.; Ramage, D.; Amin, N.; Schwikowski, B.; Ideker, T. Cytoscape: A software environment for integrated models of biomolecular interaction networks. Genome Res. 2003, 13, 2498-2504. [CrossRef] [PubMed]

34. Hu, J.X.; Thomas, C.E.; Brunak, S. Network biology concepts in complex disease comorbidities. Nat. Rev. Genet. 2016, 17, 615-629. [CrossRef] [PubMed]

35. Argyros, R.D.; Mathews, D.E.; Chiang, Y.H.; Palmer, C.M.; Thibault, D.M.; Etheridge, N.; Argyros, D.A.; Mason, M.G.; Kieber, J.J.; Schaller, G.E. Type B response regulators of Arabidopsis play key roles in cytokinin signaling and plant development. Plant Cell 2008, 20, 2102-2116. [CrossRef]

36. De la Riva, E.G.; Olmo, M.; Poorter, H.; Ubera, J.L.; Villar, R. Leaf mass per area (LMA) and its relationship with leaf structure and anatomy in 34 mediterranean woody species along a water availability gradient. PLoS ONE 2016, 11, e0148788. [CrossRef]

37. Baker, N.R. Chlorophyll fluorescence: A probe of photosynthesis in vivo. Annu. Rev. Plant Biol. 2008, 59, 89-113. [CrossRef]

38. Harbinson, J.; Genty, B.; Baker, N.R. Relationship between the quantum efficiencies of photosystems I and II in pea leaves. Plant Physiol. 1989, 90, 1029-1034. [CrossRef]

39. Penuelas, J.; Garbulsky, M.F.; Filella, I. Photochemical reflectance index (PRI) and remote sensing of plant $\mathrm{CO}_{2}$ uptake. New Phytol. 2011, 191, 596-599. [CrossRef]

40. Schmitz, C.; Ramlov, F.; de Lucena, L.A.F.; Uarrota, V.; Batista, M.B.; Sissini, M.N.; Oliveira, I.; Briani, B.; Martins, C.D.L.; Nunes, J.M.C.; et al. UVR and PAR absorbing compounds of marine brown macroalgae along a latitudinal gradient of the Brazilian coast. J. Photochem. Photobiol. B 2018, 178, 165-174. [CrossRef]

41. Morales, M.; Munne-Bosch, S. Malondialdehyde: Facts and artifacts. Plant Physiol. 2019, 180, $1246-1250$. [CrossRef]

42. Chan, K.X.; Phua, S.Y.; Crisp, P.; McQuinn, R.; Pogson, B.J. Learning the languages of the chloroplast: Retrograde signaling and beyond. Annu. Rev. Plant Biol. 2016, 67, 25-53. [CrossRef] [PubMed] 
43. Oh, E.; Yamaguchi, S.; Kamiya, Y.; Bae, G.; Chung, W.I.; Choi, G. Light activates the degradation of PIL5 protein to promote seed germination through gibberellin in Arabidopsis. Plant J. 2006, 47, 124-139. [CrossRef] [PubMed]

44. Liu, J.X.; Srivastava, R.; Howell, S.H. Stress-induced expression of an activated form of AtbZIP17 provides protection from salt stress in Arabidopsis. Plant Cell Env. 2008, 31, 1735-1743. [CrossRef] [PubMed]

45. Choudhury, F.K.; Rivero, R.M.; Blumwald, E.; Mittler, R. Reactive oxygen species, abiotic stress and stress combination. Plant J. 2017, 90, 856-867. [CrossRef]

46. Serin, E.A.; Nijveen, H.; Hilhorst, H.W.; Ligterink, W. Learning from co-expression networks: Possibilities and challenges. Front. Plant Sci. 2016, 7, 444. [CrossRef] [PubMed]

47. Gao, S.; Gao, J.; Zhu, X.; Song, Y.; Li, Z.; Ren, G.; Zhou, X.; Kuai, B. ABF2, ABF3, and ABF4 promote ABA-mediated chlorophyll degradation and leaf senescence by transcriptional activation of chlorophyll catabolic genes and senescence-associated genes in Arabidopsis. Mol. Plant 2016, 9, 1272-1285. [CrossRef]

48. Xu, Z.S.; Chen, M.; Li, L.C.; Ma, Y.Z. Functions and application of the AP2/ERF transcription factor family in crop improvement. J. Integr. Plant Biol. 2011, 53, 570-585. [CrossRef]

49. Karaba, A.; Dixit, S.; Greco, R.; Aharoni, A.; Trijatmiko, K.R.; Marsch-Martinez, N.; Krishnan, A.; Nataraja, K.N.; Udayakumar, M.; Pereira, A. Improvement of water use efficiency in rice by expression of HARDY, an Arabidopsis drought and salt tolerance gene. Proc. Natl. Acad. Sci. USA 2007, 104, 15270-15275. [CrossRef]

50. Mawlong, I.; Ali, K.; Srinivasan, R.; Rai, R.D.; Tyagi, A. Functional validation of a drought-responsive AP2/ERF family transcription factor-encoding gene from rice in Arabidopsis. Mol. Breed. 2015, 35, 163. [CrossRef]

51. Sharabi-Schwager, M.; Lers, A.; Samach, A.; Guy, C.L.; Porat, R. Overexpression of the CBF2 transcriptional activator in Arabidopsis delays leaf senescence and extends plant longevity. J. Exp. Bot. 2010, 61, 261-273. [CrossRef]

52. Koyama, T.; Nii, H.; Mitsuda, N.; Ohta, M.; Kitajima, S.; Ohme-Takagi, M.; Sato, F. A regulatory cascade involving class II ethylene response factor transcriptional repressors operates in the progression of leaf senescence. Plant Physiol. 2013, 162, 991-1005. [CrossRef] [PubMed]

53. Xie, X.L.; Xia, X.J.; Kuang, S.; Zhang, X.L.; Yin, X.R.; Yu, J.Q.; Chen, K.S. A novel ethylene responsive factor CitERF13 plays a role in photosynthesis regulation. Plant Sci. 2017, 256, 112-119. [CrossRef] [PubMed]

54. Baldoni, E.; Genga, A.; Cominelli, E. Plant MYB transcription factors: Their role in drought response mechanisms. Int. J. Mol. Sci. 2015, 16, 15811-15851. [CrossRef] [PubMed]

55. Chezem, W.R.; Clay, N.K. Regulation of plant secondary metabolism and associated specialized cell development by MYBs and bHLHs. Phytochemistry 2016, 131, 26-43. [CrossRef] [PubMed]

56. Stracke, R.; Werber, M.; Weisshaar, B. The R2R3-MYB gene family in Arabidopsis thaliana. Curr. Opin. Plant Biol. 2001, 4, 447-456. [CrossRef]

57. Kim, W.-Y.; Ali, Z.; Park, H.J.; Park, S.J.; Cha, J.-Y.; Perez-Hormaeche, J.; Quintero, F.J.; Shin, G.; Kim, M.R.; Qiang, Z.; et al. Release of SOS2 kinase from sequestration with Gigantea determines salt tolerance in Arabidopsis. Nat. Commun. 2013, 4, 1352. [CrossRef]

58. Jahns, P.; Latowski, D.; Strzalka, K. Mechanism and regulation of the violaxanthin cycle: The role of antenna proteins and membrane lipids. Biochim. Biophys. Acta 2009, 1787, 3-14. [CrossRef]

59. Hirsch, S.; Oldroyd, G.E. GRAS-domain transcription factors that regulate plant development. Plant Signal Behav. 2009, 4, 698-700. [CrossRef]

60. Engstrom, E.M.; Andersen, C.M.; Gumulak-Smith, J.; Hu, J.; Orlova, E.; Sozzani, R.; Bowman, J.L. Arabidopsis homologs of the petunia hairy meristem gene are required for maintenance of shoot and root indeterminacy. Plant Physiol. 2011, 155, 735-750. [CrossRef]

61. Ma, Z.; Hu, X.; Cai, W.; Huang, W.; Zhou, X.; Luo, Q.; Yang, H.; Wang, J.; Huang, J. Arabidopsis miR171-targeted scarecrow-like proteins bind to GT cis-elements and mediate gibberellin-regulated chlorophyll biosynthesis under light conditions. PLoS Genet. 2014, 10, e1004519. [CrossRef]

62. Vercruyssen, L.; Tognetti, V.B.; Gonzalez, N.; Van Dingenen, J.; De Milde, L.; Bielach, A.; De Rycke, R.; Van Breusegem, F.; Inze, D. GROWTH REGULATING FACTOR5 stimulates Arabidopsis chloroplast division, photosynthesis, and leaf longevity. Plant Physiol. 2015, 167, 817-832. [CrossRef] [PubMed] 
63. Yuan, Y.; Xu, X.; Gong, Z.; Tang, Y.; Wu, M.; Yan, F.; Zhang, X.; Zhang, Q.; Yang, F.; Hu, X.; et al. Auxin response factor $6 \mathrm{~A}$ regulates photosynthesis, sugar accumulation, and fruit development in tomato. Hortic. Res. 2019, 6, 85. [CrossRef] [PubMed]

64. Wang, Z.; Wang, F.; Hong, Y.; Yao, J.; Ren, Z.; Shi, H.; Zhu, J.K. The flowering repressor SVP confers drought resistance in Arabidopsis by regulating abscisic acid catabolism. Mol. Plant 2018, 11, 1184-1197. [CrossRef]

65. Danisman, S. TCP transcription factors at the interface between environmental challenges and the plant's growth responses. Front. Plant Sci. 2016, 7, 1930. [CrossRef] [PubMed]

66. Herve, C.; Dabos, P.; Bardet, C.; Jauneau, A.; Auriac, M.C.; Ramboer, A.; Lacout, F.; Tremousaygue, D. In vivo interference with AtTCP20 function induces severe plant growth alterations and deregulates the expression of many genes important for development. Plant Physiol. 2009, 149, 1462-1477. [CrossRef] [PubMed]

67. Andriankaja, M.E.; Danisman, S.; Mignolet-Spruyt, L.F.; Claeys, H.; Kochanke, I.; Vermeersch, M.; De Milde, L.; De Bodt, S.; Storme, V.; Skirycz, A.; et al. Transcriptional coordination between leaf cell differentiation and chloroplast development established by TCP20 and the subgroup Ib bHLH transcription factors. Plant Mol. Biol. 2014, 85, 233-245. [CrossRef]

68. Van Es, S.W.; van der Auweraert, E.B.; Silveira, S.R.; Angenent, G.C.; van Dijk, A.D.J.; Immink, R.G.H. Comprehensive phenotyping reveals interactions and functions of Arabidopsis thaliana TCP genes in yield determination. Plant J. 2019, 99, 316-328.

69. Danisman, S.; van der Wal, F.; Dhondt, S.; Waites, R.; de Folter, S.; Bimbo, A.; van Dijk, A.D.; Muino, J.M.; Cutri, L.; Dornelas, M.C.; et al. Arabidopsis class I and class II TCP transcription factors regulate jasmonic acid metabolism and leaf development antagonistically. Plant Physiol. 2012, 159, 1511-1523. [CrossRef]

70. Baima, S.; Possenti, M.; Matteucci, A.; Wisman, E.; Altamura, M.M.; Ruberti, I.; Morelli, G. The Arabidopsis ATHB-8 HD-zip protein acts as a differentiation-promoting transcription factor of the vascular meristems. Plant Physiol. 2001, 126, 643-655. [CrossRef]

71. Li, Y.Y.; Shen, A.; Xiong, W.; Sun, Q.L.; Luo, Q.; Song, T.; Li, Z.L.; Luan, W.J. Overexpression of OsHox32 results in pleiotropic effects on plant type architecture and leaf development in rice. Rice 2016, 9, 46. [CrossRef]

72. Galvez-Valdivieso, G.; Mullineaux, P.M. The role of reactive oxygen species in signalling from chloroplasts to the nucleus. Physiol. Plant 2010, 138, 430-439. [CrossRef] [PubMed]

73. Strasser, R. Protein quality control in the endoplasmic reticulum of plants. Annu. Rev. Plant Biol. 2018, 69, 147-172. [CrossRef] [PubMed]

74. Ruckle, M.E.; DeMarco, S.M.; Larkin, R.M. Plastid signals remodel light signaling networks and are essential for efficient chloroplast biogenesis in Arabidopsis. Plant Cell 2007, 19, 3944-3960. [CrossRef] [PubMed]

75. Andriankaja, M.; Dhondt, S.; De Bodt, S.; Vanhaeren, H.; Coppens, F.; De Milde, L.; Muhlenbock, P.; Skirycz, A.; Gonzalez, N.; Beemster, G.T.; et al. Exit from proliferation during leaf development in Arabidopsis thaliana: A not-so-gradual process. Dev. Cell 2012, 22, 64-78. [CrossRef] [PubMed]

76. Gordon, M.J.; Carmody, M.; Albrecht, V.; Pogson, B. Systemic and local responses to repeated hl stress-induced retrograde signaling in Arabidopsis. Front. Plant Sci. 2012, 3, 303. [CrossRef] [PubMed]

77. Vogel, M.O.; Moore, M.; König, K.; Pecher, P.; Alsharafa, K.; Lee, J.; Dietz, K.J. Fast retrograde signaling in response to high light involves metabolite export, mitogen-activated protein KINASE6, and AP2/ERF transcription factors in Arabidopsis. Plant Cell 2014, 26, 1151. [CrossRef]

78. Rossel, J.B.; Wilson, P.B.; Hussain, D.; Woo, N.S.; Gordon, M.J.; Mewett, O.P.; Howell, K.A.; Whelan, J.; Kazan, K.; Pogson, B.J. Systemic and intracellular responses to photooxidative stress in Arabidopsis. Plant Cell 2007, 19, 4091-4110. [CrossRef]

79. Iida, A.; Kazuoka, T.; Torikai, S.; Kikuchi, H.; Oeda, K. A zinc finger protein RHL41 mediates the light acclimatization response in Arabidopsis. Plant J. 2000, 24, 191-203. [CrossRef]

80. Vermeirssen, V.; De Clercq, I.; Van Parys, T.; Van Breusegem, F.; Van de Peer, Y. Arabidopsis ensemble reverse-engineered gene regulatory network discloses interconnected transcription factors in oxidative stress. Plant Cell 2014, 26, 4656-4679. [CrossRef]

81. Seo, P.J.; Park, C.M. Signaling linkage between environmental stress resistance and leaf senescence in Arabidopsis. Plant Signal. Behav. 2011, 6, 1564-1566. [CrossRef]

82. Zhou, X.; Jiang, Y.; Yu, D. WRKY22 transcription factor mediates dark-induced leaf senescence in Arabidopsis. Mol. Cells 2011, 31, 303-313. [CrossRef] [PubMed]

83. Zentgraf, U.; Laun, T.; Miao, Y. The complex regulation of WRKY53 during leaf senescence of Arabidopsis thaliana. Eur. J. Cell Biol. 2010, 89, 133-137. [CrossRef] [PubMed] 
84. Miao, Y.; Jiang, J.; Ren, Y.; Zhao, Z. The single-stranded DNA-binding protein WHIRLY1 represses WRKY53 expression and delays leaf senescence in a developmental stage-dependent manner in Arabidopsis. Plant Physiol. 2013, 163, 746-756. [CrossRef] [PubMed]

85. Xie, Y.; Huhn, K.; Brandt, R.; Potschin, M.; Bieker, S.; Straub, D.; Doll, J.; Drechsler, T.; Zentgraf, U.; Wenkel, S. Revoluta and WRKY53 connect early and late leaf development in Arabidopsis. Development 2014, 141, 4772-4783. [CrossRef]

86. Denekamp, M.; Smeekens, S.C. Integration of wounding and osmotic stress signals determines the expression of the AtMYB102 transcription factor gene. Plant Physiol. 2003, 132, 1415-1423. [CrossRef]

87. Efroni, I.; Han, S.K.; Kim, H.J.; Wu, M.F.; Steiner, E.; Birnbaum, K.D.; Hong, J.C.; Eshed, Y.; Wagner, D. Regulation of leaf maturation by chromatin-mediated modulation of cytokinin responses. Dev. Cell 2013, 24, 438-445. [CrossRef]

88. Di Giacomo, E.; Iannelli, M.A.; Frugis, G. TALE and Shape: How to Make a Leaf Different. Plants 2013, 2, 317-342. [CrossRef]

89. Bar, M.; Ori, N. Compound leaf development in model plant species. Curr. Opin. Plant Biol. 2015, 23, 61-69. [CrossRef]

90. Ung, N.; Lal, S.; Smith, H.M. The role of pennywise and pound-foolish in the maintenance of the shoot apical meristem in Arabidopsis. Plant Physiol. 2011, 156, 605-614. [CrossRef]

91. Lin, W.C.; Shuai, B.; Springer, P.S. The Arabidopsis lateral organ boundaries-domain gene ASYMMETRIC LEAVES2 functions in the repression of KNOX gene expression and in adaxial-abaxial patterning. Plant Cell 2003, 15, 2241-2252. [CrossRef]

92. Nadakuduti, S.S.; Holdsworth, W.L.; Klein, C.L.; Barry, C.S. KNOX genes influence a gradient of fruit chloroplast development through regulation of GOLDEN2-LIKE expression in tomato. Plant J. 2014, 78, 1022-1033. [CrossRef] [PubMed]

93. Meng, L.; Fan, Z.; Zhang, Q.; Wang, C.; Gao, Y.; Deng, Y.; Zhu, B.; Zhu, H.; Chen, J.; Shan, W.; et al. BEL1-LIKE HOMEODOMAIN 11 regulates chloroplast development and chlorophyll synthesis in tomato fruit. Plant J. 2018, 94, 1126-1140. [CrossRef] [PubMed]

94. Zheng, T.; Tan, W.; Yang, H.; Zhang, L.; Li, T.; Liu, B.; Zhang, D.; Lin, H. Regulation of anthocyanin accumulation via MYB75/HAT1/TPL-mediated transcriptional repression. PLoS Genet. 2019, 15, e1007993. [CrossRef] [PubMed]

95. Li, T.; Jia, K.P.; Lian, H.L.; Yang, X.; Li, L.; Yang, H.Q. Jasmonic acid enhancement of anthocyanin accumulation is dependent on phytochrome: A signaling pathway under far-red light in Arabidopsis. Biochem. Biophys. Res. Commun. 2014, 454, 78-83. [CrossRef] [PubMed]

96. Bhargava, A.; Mansfield, S.D.; Hall, H.C.; Douglas, C.J.; Ellis, B.E. MYB75 functions in regulation of secondary cell wall formation in the Arabidopsis inflorescence stem. Plant Physiol. 2010, 154, 1428-1438. [CrossRef]

97. Bui, L.T.; Giuntoli, B.; Kosmacz, M.; Parlanti, S.; Licausi, F. Constitutively expressed ERF-VII transcription factors redundantly activate the core anaerobic response in Arabidopsis thaliana. Plant Sci. 2015, 236, 37-43. [CrossRef]

98. Kosmacz, M.; Parlanti, S.; Schwarzlander, M.; Kragler, F.; Licausi, F.; Van Dongen, J.T. The stability and nuclear localization of the transcription factor RAP2.12 are dynamically regulated by oxygen concentration. Plant Cell Env. 2015, 38, 1094-1103. [CrossRef]

99. Briggs, G.C.; Mouchel, C.F.; Hardtke, C.S. Characterization of the plant-specific BREVIS RADIX gene family reveals limited genetic redundancy despite high sequence conservation. Plant Physiol. 2006, 140, 1306-1316. [CrossRef]

100. Maugarny-Cales, A.; Cortizo, M.; Adroher, B.; Borrega, N.; Goncalves, B.; Brunoud, G.; Vernoux, T.; Arnaud, N.; Laufs, P. Dissecting the pathways coordinating patterning and growth by plant boundary domains. PLoS Genet. 2019, 15, e1007913. [CrossRef]

101. Kierzkowski, D.; Runions, A.; Vuolo, F.; Strauss, S.; Lymbouridou, R.; Routier-Kierzkowska, A.L.; Wilson-Sanchez, D.; Jenke, H.; Galinha, C.; Mosca, G.; et al. A growth-based framework for leaf shape development and diversity. Cell 2019, 177, 1405-1418. [CrossRef]

102. Bray, N.L.; Pimentel, H.; Melsted, P.; Pachter, L. Near-Optimal probabilistic RNA-seq quantification. Nat. Biotechnol 2016, 34, 525-527. [CrossRef] [PubMed]

103. Untergasser, A.; Cutcutache, I.; Koressaar, T.; Ye, J.; Faircloth, B.C.; Remm, M.; Rozen, S.G. Primer3-new capabilities and interfaces. Nucleic Acids Res 2012, 40, e115. [CrossRef] [PubMed] 
104. Maroufi, A.; Van Bockstaele, E.; De Loose, M. Validation of reference genes for gene expression analysis in chicory (Cichorium intybus) using quantitative real-time PCR. BMC Mol. Biol. 2010, 11, 15. [CrossRef] [PubMed]

105. Muller, P.Y.; Janovjak, H.; Miserez, A.R.; Dobbie, Z. Processing of gene expression data generated by quantitative real-time RT-PCR. Biotechniques 2002, 32, 1372-1379. [PubMed]

106. Lohse, M.; Nagel, A.; Herter, T.; May, P.; Schroda, M.; Zrenner, R.; Tohge, T.; Fernie, A.R.; Stitt, M.; Usadel, B. Mercator: A fast and simple web server for genome scale functional annotation of plant sequence data. Plant Cell Env. 2014, 37, 1250-1258. [CrossRef]

107. Langfelder, P.; Horvath, S. WGCNA: An R package for weighted correlation network analysis. BMC Bioinf. 2008, 9, 559. [CrossRef]

108. Wu, T.D.; Watanabe, C.K. GMAP: A genomic mapping and alignment program for mRNA and EST sequences. Bioinformatics 2005, 21, 1859-1875. [CrossRef]

109. Wei, T.Y.; Simko, V. Visualization of a Correlation Matrix: Package 'corrplot'. 2017. Available online: https://rdrr.io/cran/corrplot/man/corrplot-package.html (accessed on 22 October 2019).

110. Maxwell, K.; Johnson, G.N. Chlorophyll fluorescence-A practical guide. J. Exp. Bot. 2000, 51, 659-668. [CrossRef]

111. Cerovic, Z.G.; Masdoumier, G.; Ghozlen, N.B.; Latouche, G. A new optical leaf-clip meter for simultaneous non-destructive assessment of leaf chlorophyll and epidermal flavonoids. Physiol. Plant 2012, 146, 251-260. [CrossRef]

112. Sumanta, N.; Haque, C.I.; Nishika, J.; Suprakash, R. Spectrophotometric analysis of chlorophylls and carotenoids from commonly grown fern species by using various extracting solvents. Res. J. Chem. Sci. 2014, 4, 63-69.

113. Castro-Esau, K.L.; Sánchez-Azofeifa, G.A.; Rivard, B. Comparison of spectral indices obtained using multiple spectroradiometers. Remote Sens. Env. 2006, 103, 276288.

114. Hodges, D.M.; DeLong, J.M.; Forney, C.F.; Prange, R.K. Improving the thiobarbituric acid-reactive-substances assay for estimating lipid peroxidation in plant tissues containing anthocyanin and other interfering compounds. Planta 1999, 207, 604-611. [CrossRef]

115. Robinson, M.D.; Oshlack, A. A scaling normalization method for differential expression analysis of RNA-seq data. Genome Biol. 2010, 11, R25. [CrossRef] [PubMed]

116. Robinson, M.D.; McCarthy, D.J.; Smyth, G.K. edgeR: A Bioconductor package for differential expression analysis of digital gene expression data. Bioinformatics 2010, 26, 139-140. [CrossRef] [PubMed] 